\title{
1 Two-speed genome expansion drives the evolution of pathogenicity in animal
}

\section{2 fungal pathogens}

4 Theresa Wacker ${ }^{1}$, Nicolas Helmstetter ${ }^{1}$, Duncan Wilson ${ }^{1}$, Matthew C. Fisher ${ }^{2}$, David J.

5 Studholme ${ }^{3}$, Rhys A. Farrer ${ }^{1, *}$.

${ }^{1}$ Medical Research Council Centre for Medical Mycology at the University of Exeter, Exeter,

8 United Kingdom

$9{ }^{2}$ MRC Centre for Global Infectious Disease Analysis, Imperial College London, London,

10 United Kingdom

$11{ }^{3}$ Biosciences, University of Exeter, Exeter, United Kingdom

$12{ }^{*}$ Corresponding author: r.farrer@exeter.ac.uk

\section{Abstract}

15 The origins of virulence in amphibian-infecting chytrids Batrachochytrium dendrobatidis ( $B d)$ and Batrachochytrium salamandrivorans (Bsal) are largely unknown. Here, we use deep nanopore sequencing of $B s a l$ and comparative genomics against 21 high-quality genome assemblies that span the fungal Chytridiomycota. Bsal has the most repeat-rich genome, comprising $40.9 \%$ repetitive elements, which has expanded to more than $3 \mathrm{X}$ the length of its conspecific Bd. M36 metalloprotease virulence factors are highly expanded in Bsal and 53\% of the 177 unique genes are flanked by transposable elements, suggesting repeat-driven expansion. The largest M36 sub-family are mostly (84\%) flanked upstream by a novel LINE element, a repeat superfamily implicated with gene copy number variations. We find that Bsal has a highly compartmentalized genome architecture, with virulence factors enriched in gene-sparse/repeat-rich compartments, while core conserved genes occur in generich/repeat-poor compartments. This is a hallmark of two-speed genome evolution. Furthermore, genes with signatures of positive selection in $B d$ are enriched in repeat-rich regions, suggesting they are a cradle for chytrid pathogenicity evolution, and $B d$ also has a two-speed genome. This is the first evidence of two-speed genomes in any animal pathogen, and sheds new light on the evolution of fungal pathogens of vertebrates driving global declines and extinctions.

\section{Introduction}

Batrachochytrium salamandrivorans (Bsal) threatens amphibians globally and is currently expanding its geographic range across Europe. It infects highly susceptible fire 
37 Spain (Beukema et al., 2021; Martel et al., 2014). This ecologically important fungal

38 pathogen belongs to the Rhizophydiales order of the Chytridiomycota which includes genera

39 with saprobic free-living as well as pathogenic life histories. For example, Entophylctis

40 helioformis and Homolaphlyctis polyrhiza are the two closest known relatives to

41 Batrachochytrium. However, unlike those amphibian pathogens, E. helioformis and $H$.

42 polyrhiza are saprotrophs found on algae and leaf litter and are unable to grow on amphibian

43 skin (Joneson et al., 2011; Longcore et al., 2012).

Bsal likely diverged from $B d$ between 30 and 115 million years ago in the Late

Cretaceous or early Paleogene, and both species have likely been endemic to Asian salamanders and newts (Urodela) for millions of years. Both species have expanded their ranges in recent time with $B d$ becoming globally established in the early to mid- $20^{\text {th }}$ Century while Bsal emerged in the Netherlands only in 2010 and spread to naïve European populations (Martel et al., 2014). Since diverging, $B d$ and Bsal have evolved to infect different amphibian species and display different pathologies. While $B d$ is a generalist pathogen that infects all three orders of amphibian, Bsal has evolved as a specialist pathogen of the Urodela order (newts and salamanders) (Martel et al., 2013), yet is able to survive asymptomatically on amphibians of other orders, potentially contributing to its spread (More et al., 2018). While $B d$ causes hyperplasia (proliferation of cells) and hyperkeratosis (thickening of the stratum corneum), Bsal causes multifocal superficial erosions and deep ulcerations in the skin of its host (Martel et al., 2013). The evolutionary route to pathogenicity and the genetic mechanisms underlying host-specificity and pathology in the Batrachochytrium genus remain largely unknown.

Evolution shapes genomes unevenly, resulting in both conserved and faster evolving genomic regions. In extreme cases, a phenomenon termed the 'two-speed genome' has been identified, whereby rapidly-evolving genes comprise a substantial portion of the genome and is associated with an enrichment of repeat families that are likely contributing to or driving gene variation (Dong et al., 2015; Faino et al., 2016b; Frantzeskakis et al., 2019;

66 Gijzen, 2009; Haas et al., 2009; Lamour et al., 2012; Raffaele et al., 2010; Raffaele \&

67 Kamoun, 2012a; Tyler et al., 2006). In plant pathogens with two-speed genomes, fast-

68 evolving regions are enriched for genes that are upregulated in planta (Raffaele et al., 2010),

69 have signatures of positive selection (Sánchez-Vallet et al., 2018), and have undergone

70 increased gene family expansions (Raffaele et al., 2010). To date, two-speed genome

71 compartmentalization has been identified in a range of fungal and oomycete plant pathogens

72 (Faino et al., 2016b; Plissonneau et al., 2016; Raffaele et al., 2010; Torres et al., 2020; Q.

73 Wang et al., 2017; Winter et al., 2018). Among the chytrids, Synchytrium endobioticum 
74 responsible for potato wart disease has been noted to have effector genes within repeat-rich regions (van de Vossenberg et al., 2019). However, there has been no comprehensive analysis or identification of two-speed genomes among the Chytridiomycota to date, or indeed among any animal pathogens.

In 2017, we sequenced Bsal's genome for the first time (R. A. Farrer et al., 2017), discovering it had an expanded genome relative to its closest relatives. We found that Bsal has undergone several large protein family expansions, including the M36 metalloproteases that are thought to be involved in the breakdown of amphibian skin and extracellular matrix (Joneson et al., 2011). The M36 metalloprotease family expansions were noted to coincide with an increase in repeat-rich regions; however, that study found only $17 \%$ of the genome assembly to be repetitive (R. A. Farrer et al., 2017). We also found evidence that unlike $B d$, Bsal does not illicit a clear immune response during infection in a shared host species (R. A. Farrer et al., 2017). However, the use of exclusively short-read sequencing limited us to a highly fragmented genome from which we were unable to fully explore its modes of genome evolution and resolve repeat-rich regions. Furthermore, the genomes of only four chytrid species were compared as opposed to the 22 chytrids investigated in the present study. Here, we use long-read nanopore sequencing to more fully understand the genome evolution of Bsal underpinning its host-range and pathogenicity.

\section{Results}

\section{The repeat-driven expansion of Batrachochytrium salamandrivorans} salamandrivorans ( $\mathrm{Bsal}$ ) revealed that it has undergone a large genome expansion compared with all known and genome-sequenced Rhizophydiales (Figure 1). Notably, the genome of $B s a l$ is $>3 X$ longer than its closest known relative $B$. dendrobatidis $(B d)$. Our updated genome assembly (version 2; v.2) is a substantial improvement on our previous

102 Illumina-based assembly (version 1; v.1). Notably, v.2 has a total length of $73.3 \mathrm{Mb}$ across

103165 supercontigs ( $N_{\text {Max }} 5.6 \mathrm{Mb}, N_{50} 0.9 \mathrm{Mb}$ ) compared with v. 1 that is $32.6 \mathrm{Mb}$ across 5,358

104 contigs $\left(N_{50} 10.5 \mathrm{~kb}\right)$ (Table S1). Bsals updated genome length elevates it to the second-

105 largest in the Chytridiomycota fungal phyla, after Cladochytrium polystormum (81.2 Mb) - a

106 species that is mainly associated with aquatic plants (Czeczuga, Mazalska, et al., 2007;

107 Czeczuga, Muszyńska, et al., 2007; Powell et al., 2018). Our updated gene annotation also

108 revealed slightly higher numbers of predicted protein-coding genes ( $n=10,867$ with a 109 combined length of $16.38 \mathrm{Mb}$ ) and was more complete (94.1\% of BUSCO core conserved

110 fungal genes) compared to the v.1 assembly (BUSCO =92.2\%). Synteny indicated there 
111 were no newly evolved or acquired chromosomes in Bsals genome, although its genome

112 expansion relative to $B d$ was accompanied by an abundance of chromosomal

113 rearrangements (Figure S1).

$B s a l$ has the most repeat-rich genome of any chytrid sequenced to date, with $40.9 \%$ (30 $\mathrm{Mb})$ of the genome predicted to be repetitive (Figure S2). Bsal has undergone a unique repeat-driven expansion compared with other chytrids including $B d$, resulting in distinct repeat family profile (Figure 2). Repeat content across the Chytridiomycota (as a percentage of genome length) has a positive monotonic correlation with genome length (Spearman's $r_{s}=0.62, p=0.0019$ ), as do transposable elements (Spearman's $r_{s}=0.56, p=$ 0.0059). Conversely, repeat content does not correlate with assembly contiguity $\left(N_{50}\right)$ (Spearman's $r_{s}=0.19, p=0.39$ ) or degree of fragmentation (number of contigs) (Spearman's $r_{s}=-0.022, p=0.92$ ) (Figure S3). Genome length in the Chytridiomycota is therefore a good predictor of repeat-richness. nuclear elements (LINE) retrotransposons are uniquely expanded in the Bsal genome compared with $\mathrm{Bd}$ (Figure 2). Bsal has the highest overall content of TEs of any chytrid (Figure S4). TEs comprise $19.36 \%$ of all Bsal repetitive content and are not uniformly distributed in the genome but appear in clusters. Conversely, repeats in general, including simple repeats are uniformly distributed (Figure S5). C. polystomum (the largest genome) has the second highest proportion of TEs (12.3\%). All other chytrids have $<10 \%$ TEs (geometric mean: $3.43 \%, \sigma: 2.52 \%$; excluding Bsal and C. polystomum), indicating that TE content associates with genome expansions. LTRs are the second most abundant repeat family in Bsal (6.6 Mb; $9 \%$ of genome), most of which (97\%) are Gypsy elements. Gypsy repeats are far less common in other Rhizophydiales including $B d(4.8 \mathrm{~kb} ; 0.02 \%$ of genome), H. polyrhiza (absent), and E. helioformis (988 kb; 3.2\%). Similarly, LINEs make up $6.4 \mathrm{Mb}(8.8 \%)$ of the Bsal genome (Table S2), yet are not detected in most of the other genomes belonging to the Rhizophydiales including H. polyrhiza, BdMADA_210 (amphibianassociated chytrid recovered from Madagascar) and Globomyces pollinis-pini (a saprotrophic chytrid found in aquatic habitats (Pm et al., 2008)). The three remaining Rhizophydiales species ( $B d$, E. helioformis and $G$. haynaldii) have only low numbers of LINE elements $(0.28 \%, 0.6 \%$ and $0.47 \%$ of genome, respectively). 
148 and biological functions were identified across the Chytridiomycota (Figure 3, Figure S6).

149 To assess differences between FIR lengths and gene categories, we characterised four

150 groups or quadrants partitioned by the 5' and 3' median intergenic distances (upper-left; QuL,

151 upper-right; $Q_{U R}$, lower-left; $Q_{L L}$ and lower-right; $Q_{L R}$ ) and tested for enrichment of genes

152 using hypergeometric tests $(\mathrm{HgT})$ and $\mathrm{X}^{2}$ tests. The set of all Bsal genes were evenly

153 dispersed across quadrants $\left(Q_{U L}=2,269\right.$ genes, $Q_{U R}=2,998$ genes, $Q_{L R}=2,268$ genes,

154 and $Q_{L L}=2,998$ genes). However, the subset of core conserved genes (CCGs) is enriched

155 in $\mathrm{Q}_{\mathrm{LL}}\left(\mathrm{HgT} p=5.88 \mathrm{E}-6, \mathrm{x}^{2}\right.$ test $\left.p=7.16 \mathrm{E}-6\right)$. Furthermore, M36 protease genes, other

156 genes encoding proteins with secretion signals and genes encoding small secreted proteins

157 (SSPs) were all enriched in QuR according to $\mathrm{HgT}(p=1.2 \mathrm{E}-38, p=5.42 \mathrm{E}-92, p=9.13 \mathrm{E}-7$,

158 respectively) and $\mathrm{X}^{2}$ tests $(p=1.93 \mathrm{E}-43, p=5.39 \mathrm{E}-102, p=4.4 \mathrm{E}-7$, respectively). This is a

159 hallmark of a two-speed genome (Table S3B-C)). Accordingly, Bsal has 3.5X more

160 repetitive sequence and 4.5X more TE in QuR compared with $Q_{L L}$ based on gene identities in $16110 \mathrm{~kb}$ non-overlapping windows (Table S3K).

FIR lengths are significantly longer for M36 proteases, genes encoding proteins with secretion signals and SSPs compared to overall mean intergenic distances in Bsal (Wilcoxon rank-sum tests: $p=1.42 \mathrm{E}-61,2.45 \mathrm{E}-121$ and 2.50E-07, respectively) (Table S3D). Mean intergenic distances for M36 proteases, genes encoding proteins with secretion signals and SSPs are also significantly longer than CCGs (Wilcoxon rank-sum tests: $p=$ 1.46E-61, 8.54E-72 and 2.4E-13, respectively). Separately, CCGs are flanked by significantly shorter intergenic regions than the genome-wide average (Wilcoxon rank-sum test $p=2.03 \mathrm{E}-09$ ) (Figure 4, Table S3D). Intriguingly, most chytrids (18 out of 23) had an enrichment of CCGs in $Q_{L L}$ and nearly half (10 out of 23 ) had an enrichment for genes encoding proteins with secretion signals in QuR ( $\mathrm{HgT}$ and $\mathrm{x}^{2}$ test $q<0.01$ ), indicating those

173 are common features of Chytidiomycota evolution. However, Bsal has the most significant

174 enrichment of genes with secretion signals in QUR of any chytrid tested ( $\mathrm{HgT} p=5.42 \mathrm{E}-92$,

$175 \mathrm{X}^{2}$-test $\left.p=5.39 \mathrm{E}-102\right)$ (Table S3B-C), while $B d$ had the second strongest enrichment $(\mathrm{HgT} p$

$176=9.75 \mathrm{E}-67, \mathrm{X}^{2}$-test $\left.p=4.18 \mathrm{E}-74\right)$.

FIR based quadrants are present throughout Bsals genome and not exclusively from individual chromosomes or large sub-chromosomal or subtelomeric regions (Figure 3F).

180 Similarly, M36 metalloproteases are encoded throughout the $\mathrm{Bsal}$ and $\mathrm{Bd}$ genomes (Figure

181 S1). Of the 28 contigs that feature a (TTAGGG) terminal telomeric repeat, 14 feature 182 clusters of up to 10 M36s or gene with secretion signal in those subtelomeric regions. Six 183 contigs overall deviate from the null hypothesis of $25 \%$ of genes populating each quadrant 184 ( $X^{2}$-test for goodness of fit; Table S4), three of which (scaffolds 94, 329 and 334) are $>1 \mathrm{Mb}$ 
185 in length. Twelve contigs were enriched for one of the quadrants $(\mathrm{Hg} \mathrm{T} p<0.01)$ including

$186 \mathrm{Q}_{\mathrm{UR}}(n=9)$ and $\mathrm{Q}_{\mathrm{LL}}(n=3)$ and no enrichments were found for either $\mathrm{QuL}_{\mathrm{L}}$ or $\mathrm{Q}_{\mathrm{LR}}$ (Table S4).

187 The longest stretch of consecutive $Q_{U R}$ genes is $16(128 \mathrm{~kb}), Q_{L L}$ genes is $13(33 \mathrm{~kb}), Q_{L R}$

188 genes is 5 (25 kb), and for $Q_{U L}$ it is only 4 (16 kb; Table S5A).

The probabilities for each set of consecutive genes from any given quadrant was calculated using a custom discrete-time pattern Markov chain approach, which identified 35 contigs with significant consecutive gene counts $(p<0.01)$ from either $Q_{U R}(n=15)$ or $Q_{\mathrm{LL}}(n$ $=20$; Table S5B). The two most significant of these were scaffold0320 with 16 consecutive genes in QuR (total genes on contig =122, $p=1.44 \mathrm{E}-07$ ) and scaffold0334 with 15 consecutive genes in $Q_{U R}$ (total genes on contig $=380, p=1.71 \mathrm{E}-06$ ). The 16 consecutive QuR genes on contig320 included 6 genes with secretion signals (three belonged to Tribe 31 (unknown function), and two belonged to Tribe 17 with a S1-P1 nuclease domain (PF02265.16)). The 15 consecutive QuR genes on scaffold0334 included only 1 gene with a secretion signal (Tribe 536, with a kelch4 galactose oxidase central domain (PF13418.6)).

Genes with long intergenic distances are associated with positive selection in $B d$. While all reported isolates of $B s a l$ to date are clonal, there have been substantial sampling efforts for $B d$ revealing five genetically diverse lineages, providing an opportunity to explore intra-population genetic variation and associations with intergenic distances, which is an opportunity not currently available for Bsal. By calculating $d N / d S(\omega)$ for every $B d$ gene in each lineage, we discovered that genes with a signature of positive selection $(\omega>1)$ were significantly enriched in QuR for each lineage (HgT $p<2.59 \mathrm{E}-10, \mathrm{X}^{2}$-test $\left.p<6.5 \mathrm{E}-11\right)$ (Table S3E). Notably, genes with $\omega>1$ and secretion signals were enriched in $Q_{U R}$ for each $B d$ lineage $\left(\mathrm{HgT} p<8.48 \mathrm{E}-13, \mathrm{X}^{2}\right.$-test $\left.p<3.64 \mathrm{E}-14\right)$. This is consistent with both Batrachochytrids ( $B d$ and $B s a l)$ having two-speed genomes.

Recently, it was shown that ricin-like B lectins play a crucial role in the initial stages of pathogenesis in Bsal (Y. Wang et al., 2021). Previous studies have also found that these lectins are expressed during exposure of Bsal to salamander skin (R. A. Farrer et al., 2017). Of the two ricin-like B lectins identified in this study, one of them, BSLG_002240, can be found in QuR, providing evidence that virulence genes are indeed sequestered to this dynamic compartment. Rhizophydiales. Clustering secreted proteins by amino acid sequence for Bsal and its three

221 closest relatives $B d, H p$ and $E h$ ), revealed 854 distinct secreted tribes, including the M36 
222 metalloproteases that is the largest ( $n=167$, of which 142 belong to Bsal; Tribe 1 ). The ten

223 largest secreted tribes encompass nearly a quarter of all secreted proteins of $B s a l, B d, H p$

224 and Eh (24.08\%; $n=593$ ) (Table S3J). Notable gene tribes included the M36s (Tribe 1),

225 polysaccharide deacetylases (Tribe 4), tyrosinases (Tribe 6), aspartyl proteases (Tribe 7),

226 phosphate-induced proteins (Tribe 8) and lipases (Tribe 10), each of which may be involved

227 in pathogenicity. Bsal genes in Tribes 1, 4, 8 and 10 are enriched in QuR. Bd genes in Tribes

228 1, 2, 3, 5, 7 and 9 are enriched in QuR (Figure 5, Table S3I-J, Table S6).

229

\section{M36 metalloprotease expansion linked to transposable elements}

Bsal encodes the most M36 metalloproteases $(n=177)$ of any other chytrid (Fig.

S1), which is $>5 \mathrm{X}$ more than $B d$ encodes $(n=35$ ) (Joneson et al., 2011). M36

metalloproteases in Bsal can be divided into six species-specific families (Bsal M36 family 1-

6) and two more evolutionary conserved families based on sequence similarity and a gene tree (Figure 6). The largest M36 sub-family ( $n=70 ; B s a /$ M36 family 6 ) was previously named Bsal G2M36 (R. A. Farrer et al., 2017) and is uniquely associated with two repeat families including the transposable LINE element rnd2 family2 (Table S2, Table S7). The majority of Bsal M36 family 6 genes are flanked by this LINE element upstream ( $n=59 / 70$; $84.3 \% ; p=3.33 \mathrm{E}-99$ ) and flanked by an uncharacterised repeat rnd1 family182 downstream (53/70; 75.7\%; $p=8.56 \mathrm{E}-75)$, as well as $67.1 \%$ of Bsal M36 family 6 are flanked either side by both repeats. No other Bsal M36 family has a flanking rnd1 family182 and only 2 Bsal M36s have a flanking rnd2 family2 (M36 families 1 and 3). The $8.8 \%$ of Bsals genome comprising LINE elements is therefore associated with its genome expansion and gene family expansion of putative virulence factors.

Bsal M36-associated repeats are highly enriched upstream and downstream of the M36 metalloprotease coding genes ( $r n d 2$ family2 upstream of M36s: $p=8.56 \mathrm{E}-75$; rnd1 family182 downstream of M36s: 3.33E-99) and genes with secretion signals (rnd2 family2 upstream of secreted: $p=4.50 \mathrm{E}-28$; rnd1 family182 downstream of secreted: $p=1.48 \mathrm{E}-42$; Table S3F-H). Rnd1 family182 and rnd2 family2 are disproportionately found in genesparse/repeat-rich compartments of the genome (QUR: $p_{\text {rnd2 family2 }}=2.53 E-25, p_{\text {rnd1 family182 }}=$ $1.16 \mathrm{E}-11)$. Rnd2 family 2 has a homologous repeat family in $B d$ (rnd1 family 109 ), which is also classified as a LINE. However, this repeat family is only present upstream of 1 M36 metalloproteases and 8 genes with secretion signals in $B d$. Rnd1 family182 has no homologous repeat family in $B d$. We found only 66/734 Bsal repeat families had homologs in emerged since it speciated with $B d$. 
259

260

261

262

263

264

265

266

267

268

269

270

271

272

273

274

275

276

277

278

279

280

281

282

283

284

285

286

287

288

289

290

291

292

\section{Discussion}

The chytridiomycosis panzootic has been identified as one of the key drivers of global amphibian declines, contributing to earth's sixth mass extinction. Since the discovery of $B d$ (Berger et al., 1998) and more recently Bsal (Martel et al., 2013), efforts have been made to understand their evolution and mechanisms of pathogenicity and virulence. Bsal's virulence is likely shaped by an "arms race" between host and pathogen, resulting in large and diverse families of proteolytic enzymes for skin and extracellular matrix destruction (R. A. Farrer et al., 2017; Fisher et al., 2021; Papkou et al., 2019). Here, we assemble and annotate an improved Bsal genome assembly and perform comparative genomics across the Chytridiomycota, discovering that both Bsal and Bd have hallmarks of two-speed genomes.

Bsal has an extremely repeat-rich genome (40.9\%) compared with most fungal species, which typically range from 5-35\% (Wöstemeyer \& Kreibich, 2002). However, there are other fungal pathogens with even greater repeat content $(>62 \%)$ such as Venturia and Blumeria species (Cam et al., 2019; Castanera et al., 2016; Frantzeskakis et al., 2018; Peter et al., 2016; Wöstemeyer \& Kreibich, 2002). Many of Bsal's repeats are transposable elements (TEs) (19.36\%) which underpin the genome expansion described in other species including the fungal wheat pathogen Zymoseptoria tritici, the barley powdery mildew, Blumeria graminis f.sp. hordei, the oomycete causative agent of potato blight, Phytophthora infestans and the symbiotic fungus Cenococcum geophilum (Oggenfuss et al., 2021; Peter et al., 2016; Raffaele \& Kamoun, 2012a; Spanu et al., 2010). TEs are abundant in the genomes of various fungal pathogens, comprising $36 \%$ of the genome for plant pathogen Leptosphaeria maculans, $64 \%$ of the genome for $B$. graminis and $74 \%$ for $P$. infestans (Grandaubert et al., 2014; Raffaele \& Kamoun, 2012a; Spanu et al., 2010). TEs in Bsals closest known relative $B d$, however, only comprises $3.37 \%$ of its genome, suggesting they have expanded recently in Bsal and that the differences in genome size in the batrachochytrids associates with TE expansion in Bsal. The most abundant TE family in Bsal is LTR/Gypsy, which is almost absent in Bd (0.02\%). LTR/Gypsy has been previously identified as a driver of genome expansion and also has been implicated with adaptation along environmental gradients and under stress 
293 conditions (Marcon et al., 2015; Pietzenuk et al., 2016; Y. Wang et al., 2018; Wos et

294 al., 2021; Zhang et al., 2020). More broadly, we found a strong correlation between

295 TE and repeat content with genome size across the Chytridiomycota. To our

296 knowledge, this is the first time that a statistical correlation between TE and repeat

297 content with genome size has been shown for an order of fungi, with previous

298 studies finding correlations in insects, chordates, larvaceans and tetrapodes, but not

299 fungi or fungal orders specifically (Canapa et al., 2015; Kidwell, 2002; Naville et al.,

300 2019).

Host-pathogen interactions exerts strong selective pressures, leading to adaptive co-evolution (Papkou et al., 2019; Tellier et al., 2014). Under Red Queen dynamics, both host and pathogen constantly adapt to the ongoing selective pressures imposed by their coevolutionary interactions, with the host's immune system evolving to detect and mount defences against the pathogen and the pathogen evolving to colonize the host (Brockhurst et al., 2014; Cook et al., 2015; Papkou et al., 2019; Torres et al., 2020; Van Valen, 1973). Pathogens with fluid genotypes may co-evolve more effectively with their host and adapt to new hosts more ably, thereby outcompeting other lineages with less plastic genomes ("clade selection") (Dong et al., 2015; Raffaele \& Kamoun, 2012b; Torres et al., 2020). Many filamentous fungal plant pathogens and oomycetes have bipartite genome architectures with gene-sparse/repeat-rich compartments enriched with effector genes (such as those coding for secreted proteins that function outside of the organism they were synthesised in), acting as "cradles of adaptive evolution" (Dong et al., 2015; Frantzeskakis et al., 2019; Haas et al., 2009; Raffaele et al., 2010; Raffaele \& Kamoun, 2012b). These repeat-rich/gene-sparse compartments are associated with higher evolvability and genome plasticity and are often enriched in TEs, feature structural and copy number variations and are enriched with genes under positive selection (Croll \& McDonald, 2012; Faino et al., 2016b; Grandaubert et al., 2014; Haas et al., 2009; Plissonneau et al., 2016; Raffaele et al., 2010; Rouxel et al., 2011; Schrader \& Schmitz, 2019). Conversely, gene-rich/repeat-sparse compartments are enriched in core conserved genes (Raffaele et al., 2010). This two-speed genome therefore provides an evolutionary solution for high evolvability in

326 the risk of excessive deleterious mutations in essential genes. 
Here we show that the batrachochytrids have such a bipartite "two-speed" genome compartmentalization, which is especially pronounced in Bsal. The genesparse compartment in both batrachochytrids are enriched in putative effector genes encoding secreted proteins, metalloproteases, and ricin B-like lectins, implicated with chemotaxis, adhesion, and the early stages of a pathogenesis (R. A. Farrer et al., 2017; Gao et al., 2019; Jousson et al., 2004; Ramakrishna Rao \& Shanmugasundaram, 1970; Shende et al., 2018; Y. Wang et al., 2021; Xu et al., 2020). In $B d$, gene-sparse compartments are enriched for genes with signatures of positive selection, indicating that the gene-sparse compartment is a hotspot of adaptive evolutionary processes in batrachochytrids. extracellular matrix during infection of the host (R. A. Farrer et al., 2017). We discovered that large gene families of Bsal M36 metalloproteases (such as family 6) are enriched for flanking LINE elements. Furthermore, LINEs are recognized as a source of gene duplications and implicated with genetic novelty where duplicated genes can evolve new functions (Chen et al., 2013; Wicker et al., 2007). Of all the chytrid genomes analysed, only Bsal and $B d$ have groups of TEs enriched around putative virulence genes, a further hallmark of two-speed genomes.

In fungi, repeats in genomes are targeted for mutation via the repeat induced point mutation (RIP) mechanism, which protects the genome from duplications and transposable element proliferation. In Bd, RIP is thought to be absent (van de Vossenberg et al., 2019). Absence of RIP is generally associated with a uniform distribution and with the erosion of compartmentalization of TEs, something that has been found in genomes lacking a compartmentalized structure before (so-called onespeed genomes) (Frantzeskakis et al., 2018, 2019). It is unknown if RIP occurs in Bsal. If RIP is absent, the observed compartmentalization of TEs, especially in the context of the uniform distribution of repeats overall, might be achieved by other mechanisms of TE silencing, such as histone modification and methylation (Deniz et al., 2019). The strong association of putative effector genes with TEs and their uneven distribution in Bsal suggests that TEs are actively and passively shaping its genome architecture, as well as driving higher evolvability of compartments enriched 
361 in virulence factors (Bao et al., 2017; Dong et al., 2015; Faino et al., 2016a;

362 Frantzeskakis et al., 2018; Grandaubert et al., 2014; Raffaele \& Kamoun, 2012b;

363 Rouxel et al., 2011; Schrader \& Schmitz, 2019).

For the first time, we discover that two important pathogens of vertebrates,

$366 B$ Bal and $B d$, have the hallmarks of two-speed genomes. Such bipartite genome

367 architectures found in several plant pathogens is therefore not limited to plant-

368 pathogens. In the batrachochytrids, their two-speed genomes underpins size and

369 content of their genome, with genes likely to be involved in pathogenicity enriched

370 within genomic compartments that allow for their rapid adaptive evolution.

\section{Figure and Table legends}

Figure 1. Phylogeny of 22 Chytrids based on multiple alignments of 143 core orthologs (left) next to genome content (right). Tree branches with a round tip have been sequenced using short-read sequencing technologies (Illumina). Tree branches with squares have been sequenced with long-read sequencing technologies (B. salamandrivorans: Oxford Nanopore sequencing technology; all others: PacBio sequencing technology). The percentage of 1000 ultrafast bootstrap resampling's that support the major topological elements in neighbour joining is indicated. The scale bar indicates the number of substitutions per site.

Figure 2. Repeat superfamily abundance in 23 Chytrids. The dendrogram is based on euclidean distances and hierarchical clustering. Only repeat families that have more than $1 \%$ abundance in at least one chytrid are included.

Figure 3. The two-speed genome of Bsal. A) a phylogenetic tree of Bsal and its three closest relatives: $\mathrm{Bd}, \mathrm{Hp}$, and $\mathrm{Eh}$ constructed using a core-ortholog multiple alignment and RAxML. Vertical branch lengths indicating the mean number of nucleotide substitutions per site. Asterisks indicate $100 \%$ bootstrap support from 1,000 replicates. Density plots of intergenic distance for all non-terminal protein coding genes are shown (measured as $\log _{10}$ length of 5' and 3' flanking intergenic distances; FIRs), with the median values shown in dotted blue line. B-E) density plots of intergenic distance for Bsal gene categories. Individual plots are non-terminal B) core-conserved genes, C) M36 metalloprotease, D) secreted genes and E) small secreted genes respectively. The median intergenic distance for all genes is shown as a dotted blue line. Asterisks indicate enrichment of genes in one of the 
396 four quadrants based on the median intergenic distances (hypergeometric test, $\mathbf{a}$-level =

0.01). F) shows the positions of $10 \mathrm{~kb}$ windows assigned to the quadrants in the genome.

Figure 4. Rhizophydiales Intergenic Distance Analysis. $\log _{10}$ mean intergenic distances of core-conserved genes (CCGs), SSPs (small secreted proteins; $<300$ aa and $\geq 4$ cysteines), secreted proteins and M36 metalloproteases for chytrids of the clade Rhizophydiales. Boxplots indicate median and interquartile range. To determine statistically significant differences of the $\log _{10}$ mean intergenic distances for pairs of different features of interest, a Wilcoxon rank-sum test was performed. P-values were Bonferroni adjusted with an a-level of 1 and $n=6 .{ }^{*}: p \leq 0.0017,{ }^{* *}: p \leq 0.00017,{ }^{* * *}: p \leq 1.7 E-5,{ }^{* * * *}: p \leq 1.7 E-6$

Figure 5. Secreted protein tribes in Bsal, Bd, Eh and Hp. The 10 biggest secreted protein tribes identified by clustering all predicted secreted genes using MCL found in one or more of the 4 chytrids Bsal, Bd, Eh, and Hp. Significance of enrichment was determined using hypergeometric tests. $Q_{U R}=$ gene-sparse region, $Q_{L L}=$ gene-rich region. Asterisks indicate enrichment of genes in one of the four quadrants (hypergeometric test, $p_{\text {adjusted }}<0.00063$ ).

Figure 6. Phylogenetic tree inferred using RaxML from protein alignments of all identified M36 proteins in four chytrids. RaxML-inferred tree of all known M36 metalloproteases in Bsal, Bd, Eh and Hp. The branch lengths (Tree scale) indicate the mean number of nucleotide substitutions per site. Upstream and downstream flanking repeat families, rnd2 family2 (LINE) and rnd1 family182 (Unknown) are indicated as circles and squares, respectively. Localization of the M36 metalloprotease genes in the gene-sparse region is indicated by triangles. G1M36 and G2M36 (as previously defined (R. A. Farrer et al., 2017)) are marked by star outlines and filled star shapes, respectively. Gene IDs: Enthel1 $=E$. helioformis, $H p=H$. polyrhiza, BSLG $=B$. salamandrivorans and $B D E G=B$. dendrobatidis.

Figure S1. Synteny plots between A) Bsal and its three closest relative $\mathrm{Bd}, \mathrm{Hp}$ and Eh, and

424 B) Bsal v.1 genome assembly and Bsal v.2 genome assembly. The positions of M36

425 metalloproteases are indicated as blue squares. The phylogenetic tree of Bsal and its three

426 closest relatives was constructed using core-ortholog multiple alignment and RAxML (with

427 WAG transition matrix). Branch lengths indicating the mean number of nucleotide

428 substitutions per site. Asterisks indicate 100\% bootstrap support from 1,000 replicates.

430 Figure S2. Overall repeat content (\%) of all 22 chytrids. Overall repeat content in percent of 431 all 22 chytrids excluding lower-scoring matches. 
433 Figure S3. Linear regression plots with Spearman correlation coefficients. A) Correlation

434 plot of transposable element content (\%) and genome length (bp) for 22 chytrids, B) repeat

435 content (\%) and the genome length, C) repeat content (\%) and $\mathrm{N} \%$ ) and $\mathbf{D}$ ) repeat content

436 and the number of contigs. R-squared $\left(R^{2}\right)$, equation of the linear equation and Spearman's

437 rank correlation coefficient are indicated in each plot. Data points are blue, the linear

438 regression line is red, the confidence interval is grey.

439

440 Figure S4. Overall content of transposable elements (\%) of all 22 chytrids. Overall content

441 of transposable elements in percent of all 22 chytrids excluding lower-scoring matches

442 (stringent criterion).

Figure S5. Repeat and TE distributions in the Bsal genome.

446 Figure S6. Density plots for all 22 chytrids analysed. Density plots of intergenic distances for

447 all non-terminal protein coding genes are shown (measured as $\log _{10}$ length of 5 ' and 3'

448 flanking upstream and downstream intergenic distances), with the median values shown in

449 dotted blue line.

451 Table S1. Whole genome assembly statistics. All genome assemblies apart from V1

452 Allpaths (R. A. Farrer et al., 2017), are de novo long read assemblies generated in this

453 study. V2 Canu default settings Pilon corrected = Bsal assembly v2.0 (our chosen assembly,

454 highlighted in blue).

456 Table S2. Repeat superfamily distributions of the 22 chytrids based on RepeatModeller

457 classifications. Lower-scoring matches were excluded. All values are in base pairs (bp).

459 Table S3. Parameters and $p$-values of hypergeometric tests, $x^{2}$-tests and Wilcoxon rank

460 sum tests. For all enrichment tests, the four quadrants ( $Q_{U L}, Q_{U R}, Q_{L R}$ and $Q_{L L}$ ) are based on

461 the 5' and 3' median $\log _{10}$ intergenic distances.

462 A) Number of M36 metalloprotease genes, genes coding for secreted proteins, small

463 secreted protein (SSP) genes and core-conserved protein (CCG) genes in all 22 chytrids.

464 SSPs are defined as either having fewer than 200 amino acids (aa; all chytrids) or proteins

465 with fewer than 200 aa and $\geq 4$ cysteines (for Rhizophydiales).

466 B) $p$-values of hypergeometric tests for enrichment of M36 metalloproteases, secreted

467 proteins, core-conserved genes and small secreted proteins (defined as smaller than 200 aa

468 and $\geq 4$ cysteines for Rhizophydiales and only as smaller than 200 aa for the rest) in the four 
469 quadrants for all 22 chytrids. Significant $p$-values ( $p_{\text {adjusted }}<0.00063$; $\alpha$-level $=0.01, n=16$ )

470 are highlighted in blue.

471 C) $p$-values for $x^{2}$-tests for enrichment of M36 metalloproteases, secreted proteins, core-

472 conserved genes and small secreted proteins (defined as smaller than 200 aa and $\geq 4$

473 cysteines for Rhizophydiales and only as smaller than 200 aa for the rest) in the four

474 quadrants for all 22 chytrids. Significant $p$-values ( $p_{\text {adjusted }}<0.00063$; $\alpha$-level $=0.01, n=16$ )

475 are highlighted in blue.

476 D) Wilcoxon rank-sum test results for distributions of all mean upstream and downstream

$477 \log _{10}$ intergenic regions compared to mean upstream and downstream $\log _{10}$ intergenic

478 regions of M36 metalloproteases, secreted proteins, core-conserved genes and small

479 secreted proteins (defined as smaller than 200 aa and $\geq 4$ cysteines for Rhizophydiales and

480 only as smaller than 200 aa for the rest) in all 22 chytrids. ${ }^{* * *}=1 \mathrm{e}-04,{ }^{* * *}=0.001,{ }^{* *}=0.01$,

$481 *=0.05, \mathrm{~ns}=1$. Significant $p$-values ( $p_{\text {adjusted }}<3.0303 \mathrm{E}-05 ;$-level $=0.01, n=330$ ) are

482 highlighted in blue.

483 E) Enrichment of M36 metalloproteases, secreted proteins, core-conserved genes and small

484 secreted proteins in $B d$ among the four Quadrants was calculated by hypergeometric tests

485 and $x^{2}$-tests ( $p$-values shown). Significant $p$-values ( $p_{\text {adjusted }}<0.0005$; $\alpha$-level $=0.01, n=20$ )

486 are highlighted in blue.

487 F) Enrichment of rnd2 family2 (LINE) and rnd1 family182 (unknown) repeat families in the

488 four quadrants in Bsal was calculated using hypergeometric tests and for $\chi^{2}$-tests ( $p$-values

489 shown). Significant $p$-values ( $p_{\text {adjusted }}<0.0025$; $\alpha$-level $=0.01, n=4$ ) are highlighted in blue.

490 G) Enrichment of repeat-families upstream and downstream of M36 metalloproteases in

491 Bsal. $p$-values are calculated for hypergeometric tests and $x^{2}$-tests. Repeat families were

492 annotated according to RepeatModeller classifications. Significant $p$-values ( $p_{\text {adjusted }}<$

4930.000083 ; $\alpha$-level $=0.01, n=120$ ) are highlighted in blue.

494 H) Enrichment of repeat-families upstream and downstream of secreted protein coding 495 genes in Bsal. $p$-values are calculated for hypergeometric tests and $x^{2}$-tests. Significant $p$ -

496 values ( $p_{\text {adjusted }}<0.00001639$; $a$-level $=0.01, n=610$ ) are highlighted in blue.

497 I) Enrichment of the 10 largest secreted tribes in the four quadrants was calculated for Bsal,

$498 B d$, Eh and Hp. $p$-values were determined using hypergeometric tests. Significant $p$-values

499 ( $p_{\text {adjusted }}<0.00063$; $a$-level $=0.01, n=16$ (four quadrants and four species for each tribe))

500 are highlighted in blue.

501 J) Numbers of genes in each secreted Tribe and the number and names of assigned

502 PFAMs. NA = Non applicable.

503 K) Details of $10 \mathrm{~kb}$ non-overlapping windows categorised according to internal gene

504 Quadrants. Windows with no predicted genes or only terminal genes were considered

505 uncharacterised (Qunchar.). 
507 Table S4. Quadrant enrichment and distribution on the chromosomes. The enrichment tests

508 for the four quadrants $Q_{U L}, Q_{U R}, Q_{L R}$ and $Q_{L L}$ are based on the 5' and 3' median $\log _{10}$

509 intergenic distances.

510 A) Enrichment of genes belonging to one of the 4 quadrants on each chromosome was

511 calculated using Hypergeometric tests, testing if there are more genes in a given quadrant

512 on that chromosome than would be expected for the overall number of genes on the

513 chromosome, given the number of genes in the quadrants in the entire genome. The

514 significance level was adjusted to $p<0.0025$ (a-level $=0.01, n=4$ ). Significant enrichments

515 are highlighted in blue.

516 B) $x^{2}$-test for goodness of fit of quadrant distribution on chromosomes. Significant deviations

517 from the distribution of numbers of genes in quadrants from the expected $25 \%$ each are

518 highlighted in blue. The significance level is Bonferroni adjusted to $p<0000633$ (a-level $=$

$5190.01, n=158)$. Obs = observed count; Exp = expected count.

520

521 Table S5. Consecutive gene counts and discrete-time Markov Chain probabilities.

522 A) Consecutive gene counts for the four quadrants ( $Q_{U L}, Q_{U R}, Q_{L R}$ and $Q_{L L}$ ) are based on the

523 5' and 3' median $\log _{10}$ intergenic distances. Start and end position of the block of

524 consecutive genes are indicated.

525 B) Probabilities for the number of consecutive genes found in the four quadrants.

526 Probabilities of finding consecutive genes of length $\mathrm{k}$ on contigs with $\mathrm{n}$ genes, computed

527 using discrete-time pattern Markov chains. Significant $($ Sig) $p$-values $(p<0.01)$ are marked

528 with *.

529 C) Longest number of consecutive genes in each of the four quadrants for each chytrid.

531 Table S6. Matching tribes of Bsal assemblies v2.0 and v1.0. Gene IDs of genes assigned to 532 the respective tribes are denoted in Bsal v2.0 Gene ID and Bsalv1.0 Gene ID. Note that IDs 533 in the same row are not homologous.

535 Table S7. M36 Metalloprotease encoding genes in the Bsal genome assembly v2.0 and

536 their matching genes and classifications according to Farrer et al. 2017 (R. A. Farrer et al.,

537 2017). Contig numbers (terminal numbers of scaffolds), gene IDs, gene IDs in Farrer et al.

538 2017, IDs of upstream flanking genes and repeats (upstream ID), IDs of downstream

539 flanking repeats and genes (downstream ID), classification as secreted (secreted) or not

540 (NA), Tribes of Bsal assembly v2.0, the matching clades in Fig. 5 and M36 clades G1M36 or

541 G2M36 designation (according to Farrer et al. 2017) of all M36 metalloproteases in Bsal

542 assembly v2.0. 
544 Table S8. Gene IDs for genes with a secretion signal, M36 metalloproteases, core-

545 conserved genes (CCGs) and short secreted proteins (SSPs) for B.salamandrivorans and $B$.

546 dendrobatidis. SSPs IDs are for SSPs defined as being shorter than 200 amino acids and

547 with $\geq 4$ cysteines.

\section{Methods}

\section{Sequencing and library preparation}

Bsal zoosporangia and zoospores were cultured in tryptone-gelatin hydrolysatelactose $(\mathrm{TgFI})$ broth in cell culture flasks at $18^{\circ} \mathrm{C}$. $200 \mathrm{ml}$ of 6 days old cultures were harvested and centrifugated at $1700 \mathrm{~g}$ for $10 \mathrm{mins}$ at $4^{\circ} \mathrm{C}$. Cell pellet was washed with ice cold water and snap frozen in liquid nitrogen. High-molecular weight DNA for Nanopore sequencing was obtained by a customized cetyltrimethylammonium bromide (CTAB) extraction procedure (Schwessinger, 2019; Schwessinger \& Rathjen, 2017) with the modification of using RNase A (T3018, NEB) instead of RNase T1. Briefly, cell pellet was ground with a mortar and pestle in liquid nitrogen with $2 \mathrm{~g}$ of sand, followed by lysis with CTAB, two-step purification with phenol/chloroform/isoamyl alcohol and precipitation with isopropanol. Care was taken to avoid DNA shearing (cut off tips, no heating of samples). DNA concentration was checked using the Qubit BR assay (Invitrogen) and DNA size range profile was checked by Tapestation gDNA screentape (Agilent).

Two independent sequencing libraries were constructed, one with long unfragmented DNA, one with DNA fragmented to $12 \mathrm{~kb}$ with a gTube (520079, Covaris). DNA ends were FFPE repaired and end-prepped/dA-tailed using the NEBNext FFPE DNA Repair kit (M6630, NEB) and the NEBNext Ultra II End-Repair/dA-tailing Module (E7546, NEB) followed by AMPure XP bead clean-up (A63882, Beckman Coulter). Adapters were ligated using the Genomic DNA by Ligation kit (SQK-LSK109, Oxford Nanopore Technologies) and

570 NEBNext Quick T4 DNA Ligase (E6056, NEB) followed by AMPure XP bead clean-up. The

571 two libraries were successively loaded onto a single PromethION (FLO-PRO002, type

572 R9.4.1) flowcell. The unfragmented library was loaded first. Guppy Basecalling Software v.

573 3.2.8+bd67289 was used for base calling. A total of 24,402,905 reads were base called and

574 of these $18,678,675$ (76.5\%) passed the quality check. Passed reads contained $63.78 \mathrm{~Gb}$ of

575 DNA sequence ( $85 \%$ of the total DNA nucleotide bases sequenced) amounting to $~ 868 \mathrm{X}$

576 depth of coverage. The mean length of nanopore read was $3,415 \mathrm{nt}$, with an $\mathrm{N}_{50}$ of 9,248

577 and a Mean Read Quality of 10.2. The longest read was 318,012nt long. 
580

Nanopore reads were trimmed using PoreChop v.0.2.3_seqan2.1 (Wick et al., 2017) with default parameters, and filtered where $<500$ bp or average read quality $>10$ using NanoFilt v.2.6.0 (De Coster et al., 2018). Canu v.1.8 (Koren et al., 2017) was used to assemble reads $\geq 100 \mathrm{~kb}$ ( $\sim 13 \mathrm{X}$ coverage) with stopOnLowCoverage $=0.5$, genomeSize $=0.6 \mathrm{~g}$ and minReadLength $=500$ (assembly name $=\mathrm{V} 2$ Canu default settings) or with additional parameters corMhapFilterThreshold=0.0000000002 corMhapOptions="-threshold 0.80 --num-hashes 512 --num-min-matches 3 --ordered-sketch-size 1000 -ordered-kmer-size 14 --min-olap-length 2000 --repeat-idf-scale 50" mhapMemory=60g mhapBlockSize $=500$ ovIMerDistinct=0.975 (assembly name $=$ V2 Canu non-default settings). Raven v1.1.10 (Vaser \& Sikic, 2019) was used to assembly all reads $\geq 50 \mathrm{~kb}$ ( 83X coverage) with default parameters (assembly name $=$ V2 Raven default settings). Medaka v.1.0.3 (https://github.com/nanoporetech/medaka; default parameters) and the trimmed nanopore reads were used for polishing. The polished assembly (V2 Canu default settings Medaka polished) and the unpolished assembly (V2 Canu default settings) were filtered for contigs $\leq 500 \mathrm{bp}$ and corrected with Illumina paired-end sequence data (R. A. Farrer et al., 2017) using Pilon v1.2 (Walker et al., 2014).

We compared the previously published assembly for $B s a l$ (assembly name $=V 1)(R$. A. Farrer et al., 2017) to our new assemblies using a variety of tools and metrics (Table S1). Assembly quality was assessed using Quast v.5.0.2 (Mikheenko et al., 2018). We evaluated each assembly for pre-annotation gene completeness using Tblastn (-e 1e-10 -v 5 -b 5 -F F) to the 248 Core Eukaryotic Genes (CEG) (Parra et al., 2007) and BUSCO v4.1.1 (Seppey et al., 2019) analysis (datasets eukaryote_odb10 and fungi_odb10). Reapr v1.0.18 (Hunt et al., 2013) was used on the assemblies with Illumina paired-end sequence data (insert size: 441). Internal duplication was assessed by MUMMER v4.0.0beta2 (Kurtz et al., 2004) nucmer (parameters --coords --maxmatch -nosimplify). Non-self-hits (>500bp and >99\% identity) were flagged as possible duplications. Dnadiff was run for comparative quantifications of duplications and gaps identified by MUMMER. While all V2 Bsal genome assemblies were improvements in multiple metrics compared with $\mathrm{V} 1$, we chose the V2 Canu default assembly polished with Pilon only for all subsequent analysis based on high accuracy, contiguity, completeness and coverage (Supplemental Material).

\section{Gene annotation}

Gene annotation on the repeat masked V2 assembly was guided by our previous 14.4Gb Bsal in vitro RNAseq (NCBI BioProject PRJNA326249) using the Braker2 (Hoff et al., 2019) pipeline (parameters --fungus, --softmasking), which uses Samtools v.0.1.1944428cd (Li et al., 2009), Bamtools v.2.4.0 (Barnett et al., 2011), Diamond v.2.0.4 (Buchfink 
617 et al., 2014), Genemark-ET v4.15 (Lomsadze et al., 2014), and Augustus v.3.2.1 (Stanke et

618 al., 2008). The pipeline identified 11,929 genes, from which $92.74 \%$ core eukaryotic genes

619 could be identified via BLASTP (e-value $<1 \mathrm{e}^{-10}$ ). Next, using the Broad Institute's Vesper

620 annotation pipeline, the genome was BLASTx against Swiss-Prot (Bairoch \& Apweiler, 2000)

621 and KEGG (Kanehisa \& Goto, 2000), and HMMER hmmscan (Finn et al., 2011) against

622 PFAM (Finn et al., 2014). We ran tRNAscan (Lowe \& Eddy, 1997) and RNAmmer (Lagesen

623 et al., 2007) to identify non-protein-coding genes. M36 genes from the V1 assembly were

624 blasted to the Braker2 softmasked predictions, and included in our gene set.

Gene predictions were checked for a variety of issues, including overlapping of noncoding genes, overlapping of coding genes, and the presence of in-frame stops. Genes were named according to evidence from BLASTx and HMMER in the following order of precedence: (i) Swiss-Pro t(Bairoch \& Apweiler, 2000), (ii) TIGRfam (Haft et al., 2003), and (iii) KEGG (Kanehisa \& Goto, 2000) (where BLASTx hits must meet the $70 \%$ identity and $70 \%$ overlap criteria to be considered a good hit and for the name to be applied). Otherwise, genes were classified as hypothetical proteins. Genes were functionally annotated by assigning PFAM (release 27) domains (Finn et al., 2014), and BLASTx for KEGG assignment (each where E-value $<1 \times 10^{-10}$ ), as well as ortholog mapping to genes of known function. SignalP 4.0 (Petersen et al., 2011) and TMHMM (Krogh et al., 2001) were used to identify secreted proteins and transmembrane proteins, respectively.

The protease composition of each chytrid was determined using top high scoring pairs from BLASTp searches (e-value $<1 \mathrm{e}^{-5}$ ) made to the file 'pepunit.lib', which is a nonredundant library of protein sequences of all the peptidases and peptidase inhibitors that are included in the MEROPS database (Release 12.1), and compared to the 447 thousand protein sequences in the 2014 version we used in our previous genomic analyses (R. A.

643 Farrer et al., 2017). All proteases with matches to M36 metalloproteases were aligned using 644 MUSCLE v3.8.31 (Edgar, 2004) and trimmed of excess gaps using trimAl 1.2rev59 645 (Capella-Gutiérrez et al., 2009) gappyout. We constructed the gene trees with RAxML 646 v7.7.8(Stamatakis, 2006) using the JTT amino acid transition model, which was visualized 647 using iTOL v6 (Letunic \& Bork, 2021).

Secreted proteins were predicted in each of the 22 chytrid species using SignalP 4.0 650 (Petersen et al., 2011). These gene sequences had their secretion signal cleaved according 651 to the predicted cleavage site, which were then clustered according to sequence similarity 652 using MCL (http://micans.org/mcl/man/clmprotocols.html) with recommended settings '-l 1.4'. 653 Secreted families were classified using PFAM domains (release 34.0) (Finn et al., 2014). 
654 Small secreted proteins (SSPs) were classified as those secreted proteins with $<300$ amino

655 acids and $>4$ cysteines.

656

\section{Chytridiomycota genomic and phylogenetic analysis}

The genomes and gene annotation for $B$. dendrobatidis $(\mathrm{Bd})$ JEL423, S. punctatus

(Sp) and H. polyrhiza (Hp) (R. A. Farrer et al., 2017) were downloaded from NCBI

660 (BioProject PRJNA13653, PRJNA37881 and GenBank AFSM00000000 respectively) and

661 FigShare (R. Farrer, 2016). Nineteen further chytrid genomes were downloaded from the

662 Mycocosm portal of the US Department of Energy (DOE) Joint Genome Institute (JGI)

663 (Grigoriev et al., 2014) including B. helicus (Ahrendt et al., 2018), C. hyalinus JEL632, C.

664 lagenaria Arg66, Chytriomyces sp. nov. MP71, E. helioformis JEL805, F. jonesii JEL569, G.

665 haynaldii MP57, G. pollinis-pini Arg68, G. prolifer a(Chang et al., 2015), G. semiglobifer Barr

666 43, G. variabilis JEL559, H. curvatum SAG235-1, O. mucronatum JEL802, P. hirtus BR81,

667 R. globosum JEL800 (Mondo et al., 2017), T. arcticum BR59, C. replicatum JEL714

668 (Mozley-Standridge et al., 2009) and C. polystomum WB228. We excluded B. helicus from

669 further analysis as it had $<75 \%$ complete BUSCOs, suggesting the assembly or gene calls

670 are incomplete.

Single copy orthologs were identified between chytrids using the Synima (R. A.

Farrer, 2017) pipeline with Orthofinder, and aligned using MUSCLE v3.8.31 (Edgar, 2004). A

maximum likelihood tree was constructed using IQ-Tree v1.6.12 (Nguyen et al., 2015, p.)

with the LG amino acid substitution model (the best fitting model according to ProtTest

v3.4.2 (Darriba et al., 2011)) with 1000 ultrafast bootstraps, and visualized using Figtree v1.4.4 with midpoint rooting.

\section{Repeat Analysis}

Repeat content was identified using Repeatmodeller v.2.0.1 (Flynn et al., 2020) with rmblast v.2.10.0+ and Tandem Repeat Finder v.4.09(Benson, 1999), RepeatScout v.1.06 and RepeatMasker v.4.0.5 (Smit et al., 2015). The output of Repeatmodeller

683 (consensi.fa.classified) was then used as a library for RepeatMasker. The repeat content

684 and family distribution for each chytrid species was determined from RepeatMasker.out,

685 excluding lower scoring matches whose domain partly $(<80 \%)$ includes the domain of

686 another match.

TE and repeat distributions in the genome were assessed using Repeatmasker .gff 689 outfiles and visualized using IGV 2.8.2 (Robinson et al., 2011). TE distribution in relation to 690 GC content was analyzed using Pilon's GC.wig files. Additionally, TE and repeat content of 
691 10kb windows assigned to different quadrants was calculated using custom scripts based on

692 RepeatMasker .out files \& lists of genes assigned to quadrants.

693

To assess if repeat content was correlated to genome assembly quality, Spearman's Rank Correlation Coefficients, Spearman's correlation and linear regression (linear model

696 fitting based on formula by Wilkinson and Rogers (1973) (Wilkinson \& Rogers, 1973)) were calculated between repeat content and $\mathrm{N}_{50}$, the number of contigs, genome length, as well as the number of genes using ggpubr (https://github.com/kassambara/ggpubr).

For the heatmap showing repeat superfamily profiles, heatmap. 2 was used with hierarchical clustering and Euclidian as a distance measure. Repeat families that did not exceed $1 \%$ abundance in any of the chytrids were excluded. Repeat families in Bd and Bsal were aligned using blastn with an e-value of 0.01 , no filtering (-dust no, -soft_masking false) and a wordsize of 7 to determine homologs. Telomeric sequences were manually curated.

\section{Genome compartmentalization analysis}

Flanking intergenic distance was calculated for all non-terminal protein coding genes. For each chytrid species, the median distance was used define four quadrants: Density plots of intergenic distances were constructed for all non-terminal protein coding genes, and several gene subsets including genes with a secretion signal, SSPs, conserved chytrid BUSCO genes and M36 metalloproteases. The median 5' and 3' intergenic distance for all protein coding genes in a given species was used to define four quadrants including bottom left (gene-rich/repeat-sparse), top right (gene-poor/repeat-rich), bottom right (long 3' intergenic distance, short 5' intergenic distance) and top left (short 3 ' intergenic distance,

715 long 5 ' intergenic distance).

To identify enrichment of gene categories in each quadrant, Hypergeometric tests

718 were performed on all genes, the aforementioned four gene categories, and the largest 10 719 secreted families (determined by MCL). Hypergeometric tests were also used to determine

720 enrichment for flanking repeat families and to determine whether genes falling in one of the 721 quadrants are enriched on certain chromosomes compared to the overall distribution of 722 genes in quadrants on all chromosomes. Critical $p$-values for hypergeometric and $\mathrm{X}^{2}$ 723 enrichments were determined using Bonferroni correction with an a-level of 0.01 . For gene 724 category enrichment, we performed 16 tests $=0.00063$. For secreted families and quadrant 725 enrichments tests on chromosomes, we performed 4 tests $=0.0025$. For flanking repeat 726 families, the correction was adjusted based on the total number of repeat families flanking. 
728 There is currently no known population structure of $B s a l$, thereby precluding the

729 study of intra-population genetic variation. However, there are multiple lineages of $B d$

730 described (R. A. Farrer et al., 2011; O'Hanlon et al., 2018) and therefore genetic variation for

731 this species can be compared to intergenic distance. Paired-end Illumina data from

732 representatives of all five known lineages (BdGPL JEL423, BdCAPE TF5a1, BdCH ACON,

733 BdAsia-1 KRBOOR_323, BdAsia-2 CLFT065, and a hybrid of unknown parentage SA-EC3)

734 were obtained from the NCBI Sequence Read Archive (SRA) (R. A. Farrer et al., 2011,

735 2013; O'Hanlon et al., 2018). The Genome Analysis Toolkit (GATK) v.4.1.2.0 (McKenna et

736 al., 2010) was used to call variants. Our Workflow Description Language (WDL) scripts were

737 executed by Cromwell workflow execution engine v.48 (Voss et al., 2017). Briefly, raw

738 sequences were pre-processed by mapping reads to the reference genome Bd JEL423

739 using BWA-MEM v.0.7.17 (Li, 2013). Next, duplicates were marked, and the resulting file

740 was sorted by coordinate order. Intervals were created using a custom bash script allowing

741 parallel analysis of large batches of genomics data. Using the scatter-gather approach,

742 HaplotypeCaller was executed in GVCF mode with the diploid ploidy flag. Variants were

743 imported to GATK 4 GenomicsDB and hard filtered (QD <2.0, FS > 60.0, $\mathrm{MQ}<40.0, \mathrm{GQ} \geq$

$74450, A D \geq 0.8, D P \geq 10$ ). The direction and magnitude of natural selection for each lineage

745 was assessed by measuring the rates of non-synonymous substitution $(d M)$, synonymous

746 substitution $(d S)$ and omega $(\omega=d N / d S)$ using the yn00 program of PAML (Yang, 2007)

747 implementing the Yang and Nielsen method, taking into account codon bias (Yang \&

748 Nielsen, 2000). The program was run on every gene in each isolate using the standard

749 nuclear code translation table. Hypergeometic tests were calculated for genes with $\omega>1$ in

750 each quadrant. We performed 20 tests per lineage, thus the $p$-value was Bonferroni

751 corrected to 0.0005 at an a-level of 0.01

752

$\mathrm{X}^{2}$ enrichments tests of independence were performed on a range of genes including

754 1) genes with a secretion signal, 2) SSPs, 3) conserved chytrid BUSCO genes, 4) repeat

755 families flanking genes coding for secreted proteins, 5) M36 metalloproteases and 6) Bd

756 genes that have $\omega>1$. Briefly, $2 \times 2$ contingency tables were generated for each test,

757 comprising two groups of dichotomous variables (number of genes in or not in the gene

758 category of interest, and the number of genes in or not in a given quadrant). $X^{2}$ - tests for

759 goodness of fit were performed to determine whether the distribution of genes within each

760 quadrant was significantly different from the expected distribution (25\% each). $\mathrm{X}^{2}$ - tests were

761 performed on each contig iteratively to test for genomic hot-spots for rapid evolution. 
763

Wilcoxon rank-sum tests were computed to test the null hypothesis that the $\log _{10}$ mean intergenic distances of the feature category of interest (SSPs, HKGs, M36 metalloproteases and secreted proteins only) and the $\log _{10}$ mean intergenic distances of all the other genes that are either a) not in that feature category of interest or b) of a different feature category have the same continuous distribution. Wilcoxon rank-sum tests were performed using Rstatix v0.7 (https://cran.r-project.org/web/packages/rstatix/index.html) wilcox_test (conf.level=0.95). Wilcoxon effectsize was determined using Rstatix wilcox_effsize (conf.level=0.95,nboot=1000 and ci=TRUE). For Wilcoxon rank sum tests, the adjusted $p$-values in the violin plots for $a$-levels of 0.01 to 0.0001 and 6 tests were as follows: ns: $p>0.0017,{ }^{*}: p<=0.0017,{ }^{* *}: p \leq 0.00017,{ }^{* * *}: p \leq 1.7 E-5,{ }^{* * * *}: p \leq 1.7 E-6$.

Consecutive gene counts were generated using lists of genes assigned to their quadrants as defined above and a bespoke script. To assess the significance of finding a certain number $\mathrm{k}$ of consecutive genes of the same quadrant, discrete pattern markov chains were used. The probability of transitioning from one quadrant to the next was set to 0.25 . Based on that, $a(k+1) \times(k+1)$ transition matrix was generated. Once the transition matrix was constructed, for a given value of $n$ the probability of having the number of consecutive genes of a certain quadrant in the chain was $P(W \mid n)=\{P n\} 0_{, k}$. In the calculation, $n$ was set to 100 repetitions of equiprobable outcome. $W$ is the event of the occurrence of $k$ consecutive genes of the same quadrant.

\section{Data availability}

Raw B. salamandrivorans sequences are deposited at GenBank under Bioproject PRJNA666901. The genome assembly and annotations for Bsal are deposited at GenBank under Bioproject PRJNA666901.

\section{Acknowledgments}

RAF and NH are supported by MRC grant MR/N006364/2 and a Wellcome Trust Seed Award (215239/Z/19/Z). TW is supported by an MRC Studentship (112189-G). This project utilised equipment funded by the UK Medical Research Council (MRC) Clinical Research Infrastructure Initiative (award number MR/M008924/1).

\section{References}

Ahrendt, S. R., Quandt, C. A., Ciobanu, D., Clum, A., Salamov, A., Andreopoulos, B., Cheng, J.-F., Woyke, T., Pelin, A., Henrissat, B., Reynolds, N. K., Benny, G. L., Smith, M. E., James, T. Y., \& Grigoriev, I. V. (2018). Leveraging single-cell 
genomics to expand the fungal tree of life. Nature Microbiology, 3(12), 1417-1428.

801 Bairoch, A., \& Apweiler, R. (2000). The SWISS-PROT protein sequence database and its supplement TrEMBL in 2000. Nucleic Acids Research, 28(1), 45-48.

Bao, J., Chen, M., Zhong, Z., Tang, W., Lin, L., Zhang, X., Jiang, H., Zhang, D., Miao, C.,

Barnett, D. W., Garrison, E. K., Quinlan, A. R., Str $\square$ mberg, M. P., \& Marth, G. T. (2011).

819 Beukema, W., Erens, J., Schulz, V., Stegen, G., Sluijs, A. S. der, Stark, T., Laudelout, A., 
824 Brockhurst, M. A., Chapman, T., King, K. C., Mank, J. E., Paterson, S., \& Hurst, G. D. D.

825 (2014). Running with the Red Queen: The role of biotic conflicts in evolution.

826 Proceedings of the Royal Society B: Biological Sciences, 281(1797), 20141382.

827 https://doi.org/10.1098/rspb.2014.1382

828 Buchfink, B., Xie, C., \& Huson, D. H. (2014). Fast and sensitive protein alignment using DIAMOND. Nature Methods, 12(1), 59-60. https://doi.org/10.1038/nmeth.3176

830 Cam, B. L., Sargent, D., Gouzy, J., Amselem, J., Bellanger, M.-N., Bouchez, O., Brown, S.,

831 Caffier, V., Gracia, M. D., Debuchy, R., Duvaux, L., Payen, T., Sannier, M., Shiller,

832 J., Collemare, J., \& Lemaire, C. (2019). Population Genome Sequencing of the Scab

833 Fungal Species Venturia inaequalis, Venturia pirina, Venturia aucupariae and

834 Venturia asperata. G3: Genes, Genomes, Genetics, 9(8), 2405-2414.

835 https://doi.org/10.1534/g3.119.400047

836 Canapa, A., Barucca, M., Biscotti, M. A., Forconi, M., \& Olmo, E. (2015). Transposons,

837 Genome Size, and Evolutionary Insights in Animals. Cytogenetic and Genome

$838 \quad$ Research, 147(4), 217-239. https://doi.org/10.1159/000444429

839 Capella-Gutiérrez, S., Silla-Martínez, J. M., \& Gabaldón, T. (2009). trimAl: A tool for 840 automated alignment trimming in large-scale phylogenetic analyses. Bioinformatics

841 (Oxford, England), 25(15), 1972-1973. https://doi.org/10.1093/bioinformatics/btp348

842 Castanera, R., López-Varas, L., Borgognone, A., LaButti, K., Lapidus, A., Schmutz, J.,

843 Grimwood, J., Pérez, G., Pisabarro, A. G., Grigoriev, I. V., Stajich, J. E., \& Ramírez,

844 L. (2016). Transposable Elements versus the Fungal Genome: Impact on Whole-

845 Genome Architecture and Transcriptional Profiles. PLOS Genetics, 12(6), e1006108.

846 https://doi.org/10.1371/journal.pgen.1006108

847 Chang, Y., Wang, S., Sekimoto, S., Aerts, A. L., Choi, C., Clum, A., LaButti, K. M.,

848 Lindquist, E. A., Yee Ngan, C., Ohm, R. A., Salamov, A. A., Grigoriev, I. V., 
Spatafora, J. W., \& Berbee, M. L. (2015). Phylogenomic Analyses Indicate that Early

Chen, S., Krinsky, B. H., \& Long, M. (2013). New genes as drivers of phenotypic evolution.

854 Cook, D. E., Mesarich, C. H., \& Thomma, B. P. H. J. (2015). Understanding Plant Immunity as a Surveillance System to Detect Invasion. Annual Review of Phytopathology, 53(1), 541-563. https://doi.org/10.1146/annurev-phyto-080614-120114 (Straminipila) on fruit tree petals floating in water. Biological Letters, 44(1). straminipilous organisms on decomposing fragments of wetland plants. Mycologia Balcanica, 4, 31-44.

867 De Coster, W., D’Hert, S., Schultz, D. T., Cruts, M., \& Van Broeckhoven, C. (2018).

868 NanoPack: Visualizing and processing long-read sequencing data. Bioinformatics, 34(15), 2666-2669. https://doi.org/10.1093/bioinformatics/bty149 
873 Dong, S., Raffaele, S., \& Kamoun, S. (2015). The two-speed genomes of filamentous

874 pathogens: Waltz with plants. Current Opinion in Genetics \& Development, 35, 5765. https://doi.org/10.1016/j.gde.2015.09.001

Edgar, R. C. (2004). MUSCLE: A multiple sequence alignment method with reduced time and space complexity. BMC Bioinformatics, 5, 113. https://doi.org/10.1186/1471$2105-5-113$

Faino, L., Seidl, M. F., Shi-Kunne, X., Pauper, M., Berg, G. C. M. van den, Wittenberg, A.

Faino, L., Seidl, M. F., Shi-Kunne, X., Pauper, M., Berg, G. C. M. van den, Wittenberg, A.

Farrer, R. (2016). Homolaphlyctis polyrhiza annotation GFF3. Figshare. Dataset. https://doi.org/10.6084/m9.figshare.4291274.v2

889 Farrer, R. A. (2017). Synima: A synteny imaging tool for annotated genome assemblies. BMC Bioinformatics, 18(1), 507. https://doi.org/10.1186/s12859-017-1939-7

891 Farrer, R. A., Henk, D. A., Garner, T. W. J., Balloux, F., Woodhams, D. C., \& Fisher, M. C.

892 (2013). Chromosomal copy number variation, selection and uneven rates of 893 recombination reveal cryptic genome diversity linked to pathogenicity. PLOS Genet, 9(8), e1003703. https://doi.org/10.1371/journal.pgen.1003703

895 Farrer, R. A., Martel, A., Verbrugghe, E., Abouelleil, A., Ducatelle, R., Longcore, J. E., 
897

898

899

900

901

902

903

904

905

906

907

908

909

910

911

912

913

914

915

916

917

918

919

920

921

innovations linked to infection strategies across emerging pathogenic chytrid fungi. Nature Communications, 8. https://doi.org/10.1038/ncomms14742

Farrer, R. A., Weinert, L. A., Bielby, J., Garner, T. W. J., Balloux, F., Clare, F., Bosch, J., Cunningham, A. A., Weldon, C., du Preez, L. H., Anderson, L., Pond, S. L. K., Shahar-Golan, R., Henk, D. A., \& Fisher, M. C. (2011). Multiple emergences of genetically diverse amphibian-infecting chytrids include a globalized hypervirulent recombinant lineage. Proceedings of the National Academy of Sciences of the United States of America, 108(46), 18732-18736. https://doi.org/10.1073/pnas.1111915108

Finn, R. D., Bateman, A., Clements, J., Coggill, P., Eberhardt, R. Y., Eddy, S. R., Heger, A., Hetherington, K., Holm, L., Mistry, J., Sonnhammer, E. L. L., Tate, J., \& Punta, M. (2014). Pfam: The protein families database. Nucleic Acids Research, 42(Database issue), D222-D230. https://doi.org/10.1093/nar/gkt1223

Finn, R. D., Clements, J., \& Eddy, S. R. (2011). HMMER web server: Interactive sequence similarity searching. Nucleic Acids Research, 39(Web Server issue), W29-W37. https://doi.org/10.1093/nar/gkr367

Fisher, M. C., Pasmans, F., \& Martel, A. (2021). Virulence and Pathogenicity of Chytrid Fungi Causing Amphibian Extinctions. Annual Review of Microbiology, 75(1), null. https://doi.org/10.1146/annurev-micro-052621-124212

Flynn, J. M., Hubley, R., Goubert, C., Rosen, J., Clark, A. G., Feschotte, C., \& Smit, A. F. (2020). RepeatModeler2 for automated genomic discovery of transposable element families. Proceedings of the National Academy of Sciences of the United States of America, 117(17), 9451-9457. https://doi.org/10.1073/pnas.1921046117

Frantzeskakis, L., Kracher, B., Kusch, S., Yoshikawa-Maekawa, M., Bauer, S., Pedersen, C., Spanu, P. D., Maekawa, T., Schulze-Lefert, P., \& Panstruga, R. (2018). Signatures of host specialization and a recent transposable element burst in the dynamic one-speed 
922

923

924

925

926

927

928

929

930

931

932

933

934

935

936

937

938

939

940

941

942

943

944

945

946

genome of the fungal barley powdery mildew pathogen. BMC Genomics, 19(1), 381. https://doi.org/10.1186/s12864-018-4750-6

Frantzeskakis, L., Kusch, S., \& Panstruga, R. (2019). The need for speed: Compartmentalized genome evolution in filamentous phytopathogens. Molecular Plant Pathology, 20(1), 3-7. https://doi.org/10.1111/mpp.12738

Gao, F., Zhang, B.-S., Zhao, J.-H., Huang, J.-F., Jia, P.-S., Wang, S., Zhang, J., Zhou, J.-M., \& Guo, H.-S. (2019). Deacetylation of chitin oligomers increases virulence in soilborne fungal pathogens. Nature Plants, 5(11), 1167-1176. https://doi.org/10.1038/s41477-019-0527-4

Gijzen, M. (2009). Runaway repeats force expansion of the Phytophthora infestans genome. Genome Biology, 10(10), 241. https://doi.org/10.1186/gb-2009-10-10-241

Grandaubert, J., Lowe, R. G., Soyer, J. L., Schoch, C. L., Van de Wouw, A. P., Fudal, I., Robbertse, B., Lapalu, N., Links, M. G., Ollivier, B., Linglin, J., Barbe, V., Mangenot, S., Cruaud, C., Borhan, H., Howlett, B. J., Balesdent, M.-H., \& Rouxel, T. (2014). Transposable element-assisted evolution and adaptation to host plant within the Leptosphaeria maculans-Leptosphaeria biglobosa species complex of fungal pathogens. BMC Genomics, 15(1), 891. https://doi.org/10.1186/1471-2164-15-891

Grigoriev, I. V., Nikitin, R., Haridas, S., Kuo, A., Ohm, R., Otillar, R., Riley, R., Salamov, A., Zhao, X., Korzeniewski, F., Smirnova, T., Nordberg, H., Dubchak, I., \& Shabalov, I. (2014). MycoCosm portal: Gearing up for 1000 fungal genomes. Nucleic Acids Research, 42(D1), D699-D704. https://doi.org/10.1093/nar/gkt1183

Haas, B. J., Kamoun, S., Zody, M. C., Jiang, R. H. Y., Handsaker, R. E., Cano, L. M., Grabherr, M., Kodira, C. D., Raffaele, S., Torto-Alalibo, T., Bozkurt, T. O., Ah-Fong, A. M. V., Alvarado, L., Anderson, V. L., Armstrong, M. R., Avrova, A., Baxter, L., Beynon, J., Boevink, P. C., ... Nusbaum, C. (2009). Genome sequence and analysis of 
947

948

949

950

951

952

953

954

955

956

957

958

959

960

961

962

963

964

965

966

967

968

969

970

971

the Irish potato famine pathogen Phytophthora infestans. Nature, 461(7262), 393398. https://doi.org/10.1038/nature08358

Haft, D. H., Selengut, J. D., \& White, O. (2003). The TIGRFAMs database of protein families. Nucleic Acids Research, 31(1), 371-373.

Hoff, K. J., Lomsadze, A., Borodovsky, M., \& Stanke, M. (2019). Whole-genome annotation with BRAKER. In M. Kollmar (Ed.), Methods in Molecular Biology (1962nd ed., pp. 62-95). Humana, New York, NY.

Hunt, M., Kikuchi, T., Sanders, M., Newbold, C., Berriman, M., \& Otto, T. D. (2013). REAPR: A universal tool for genome assembly evaluation. Genome Biology, 14(5). https://doi.org/10.1186/gb-2013-14-5-r47

Joneson, S., Stajich, J. E., Shiu, S.-H., \& Rosenblum, E. B. (2011). Genomic transition to pathogenicity in chytrid fungi. PLOS Pathog, 7(11), e1002338. https://doi.org/10.1371/journal.ppat.1002338

Jousson, O., Léchenne, B., Bontems, O., Capoccia, S., Mignon, B., Barblan, J., Quadroni, M., \& Monod, M. 2004. (2004). Multiplication of an ancestral gene encoding secreted fungalysin preceded species differentiation in the dermatophytes Trichophyton and Microsporum. Microbiology, 150(2), 301-310. https://doi.org/10.1099/mic.0.26690-0

Kanehisa, M., \& Goto, S. (2000). KEGG: Kyoto encyclopedia of genes and genomes. Nucleic Acids Research, 28(1), 27-30.

Kidwell, M. G. (2002). Transposable elements and the evolution of genome size in eukaryotes. Genetica, 115(1), 49-63. https://doi.org/10.1023/A:1016072014259

Koren, S., Walenz, B. P., Berlin, K., Miller, J. R., Bergman, N. H., \& Phillippy, A. M. (2017). Canu:scalable and accurate long-read assembly via adaptive k-mer weighting and repeat separation. Genome Research, 27(2), 722-736. https://doi.org/10.1101/gr.215087.116.Freely 
972 Krogh, A., Larsson, B., von Heijne, G., \& Sonnhammer, E. L. (2001). Predicting

973 transmembrane protein topology with a Hidden Markov Model: Application to

974 complete genomes. Journal of Molecular Biology, 305(3), 567-580.

975 https://doi.org/10.1006/jmbi.2000.4315

976 Kurtz, S., Phillippy, A., Delcher, A. L., Smoot, M., Shumway, M., Antonescu, C., \&

977 Salzberg, S. L. (2004). Versatile and open software for comparing large genomes.

978 Genome Biology, 5(2). https://doi.org/10.1186/gb-2004-5-2-r12

979 Lagesen, K., Hallin, P., Rødland, E. A., Staerfeldt, H.-H., Rognes, T., \& Ussery, D. W.

980 (2007). RNAmmer: Consistent and rapid annotation of ribosomal RNA genes.

981 Nucleic Acids Research, 35(9), 3100-3108. https://doi.org/10.1093/nar/gkm160

982 Lamour, K. H., Mudge, J., Gobena, D., Hurtado-Gonzales, O. P., Schmutz, J., Kuo, A.,

983 Miller, N. A., Rice, B. J., Raffaele, S., Cano, L. M., Bharti, A. K., Donahoo, R. S.,

984 Finley, S., Huitema, E., Hulvey, J., Platt, D., Salamov, A., Savidor, A., Sharma, R., ...

985 Kingsmore, S. F. (2012). Genome sequencing and mapping reveal loss of

986 heterozygosity as a mechanism for rapid adaptation in the vegetable pathogen

987 Phytophthora capsici. Molecular Plant-Microbe Interactions $\square:$ MPMI, 25(10),

1350-1360. https://doi.org/10.1094/MPMI-02-12-0028-R

989 Letunic, I., \& Bork, P. (2021). Interactive Tree Of Life (iTOL) v5: An online tool for

$990 \quad$ phylogenetic tree display and annotation. Nucleic Acids Research, 49(W1), W293-

$991 \quad$ W296. https://doi.org/10.1093/nar/gkab301

992 Li, H. (2013). Aligning sequence reads, clone sequences and assembly contigs with BWA-

993 MEM. ArXiv:1303.3997 [q-Bio]. http://arxiv.org/abs/1303.3997

994 Li, H., Handsaker, B., Wysoker, A., Fennell, T., Ruan, J., Homer, N., Marth, G., Abecasis,

995 G., \& Durbin, R. (2009). The Sequence Alignment/Map format and SAMtools.

996 Bioinformatics, 25(16), 2078-2079. https://doi.org/10.1093/bioinformatics/btp352 
997 Lomsadze, A., Burns, P. D., \& Borodovsky, M. (2014). Integration of mapped RNA-Seq

998 reads into automatic training of eukaryotic gene finding algorithm. Nucleic Acids

999 Research, 42(15), 1-8. https://doi.org/10.1093/nar/gku557

1000 Longcore, J. E., Letcher, P. M., \& James, T. Y. (2012). Homolaphlyctis polyrhiza gen. Et sp.

1001 Nov., a species in the Rhizophydiales (Chytridiomycetes) with multiple rhizoidal

1002 axes. Mycotaxon, 118(1), 433-440. https://doi.org/10.5248/118.433

1003 Lowe, T. M., \& Eddy, S. R. (1997). tRNAscan-SE: A program for improved detection of

1004 transfer RNA genes in genomic sequence. Nucleic Acids Research, 25(5), 955-964.

1005 Marcon, H. S., Domingues, D. S., Silva, J. C., Borges, R. J., Matioli, F. F., de Mattos Fontes,

1006 M. R., \& Marino, C. L. (2015). Transcriptionally active LTR retrotransposons in

1007 Eucalyptus genus are differentially expressed and insertionally polymorphic. BMC

1008 Plant Biology, 15(1), 198. https://doi.org/10.1186/s12870-015-0550-1

1009 Martel, A., Blooi, M., Adriaensen, C., Van Rooij, P., Beukema, W., Fisher, M. C., Farrer, R.

1010 A., Schmidt, B. R., Tobler, U., Goka, K., Lips, K. R., Muletz, C., Zamudio, K. R.,

1011 Bosch, J., Lötters, S., Wombwell, E., Garner, T. W. J., Cunningham, A. A., Spitzen-

1012 van der Sluijs, A., ... Pasmans, F. (2014). Wildlife disease. Recent introduction of a

1013 chytrid fungus endangers Western Palearctic salamanders. Science (New York, N.Y.),

1014 346(6209), 630-631. https://doi.org/10.1126/science.1258268

1015 Martel, A., Spitzen-van der Sluijs, A., Blooi, M., Bert, W., Ducatelle, R., Fisher, M. C.,

1016 Woeltjes, A., Bosman, W., Chiers, K., Bossuyt, F., \& Pasmans, F. (2013).

1017 Batrachochytrium salamandrivorans sp. Nov. causes lethal chytridiomycosis in

1018 amphibians. Proceedings of the National Academy of Sciences of the United States of

1019 America, 110(38), 15325-15329. https://doi.org/10.1073/pnas.1307356110

1020 McKenna, A., Hanna, M., Banks, E., Sivachenko, A., Cibulskis, K., Kernytsky, A.,

1021 Garimella, K., Altshuler, D., Gabriel, S., Daly, M., \& DePristo, M. A. (2010). The 
1022

1023

1024

1025

1026

1027

Genome Analysis Toolkit: A MapReduce framework for analyzing next-generation DNA sequencing data. Genome Research, 20(9), 1297-1303. https://doi.org/10.1101/gr.107524.110

Mikheenko, A., Prjibelski, A., Saveliev, V., Antipov, D., \& Gurevich, A. (2018). Versatile genome assembly evaluation with QUAST-LG. Bioinformatics, 34(13), i142-i150. https://doi.org/10.1093/bioinformatics/bty266

Mondo, S. J., Dannebaum, R. O., Kuo, R. C., Louie, K. B., Bewick, A. J., LaButti, K., Haridas, S., Kuo, A., Salamov, A., Ahrendt, S. R., Lau, R., Bowen, B. P., Lipzen, A., Sullivan, W., Andreopoulos, B. B., Clum, A., Lindquist, E., Daum, C., Northen, T. R., ... Grigoriev, I. V. (2017). Widespread adenine N6-methylation of active genes in fungi. Nature Genetics, 49(6), 964-968. https://doi.org/10.1038/ng.3859

More, S., Miranda, M. A., Bicout, D., Bøtner, A., Butterworth, A., Calistri, P., Depner, K., Edwards, S., Garin-Bastuji, B., Good, M., Michel, V., Raj, M., Nielsen, S. S., Sihvonen, L., Spoolder, H., Stegeman, J. A., Thulke, H.-H., Velarde, A., Willeberg, P., ... Schmidt, C. G. (2018). Risk of survival, establishment and spread of Batrachochytrium salamandrivorans (Bsal) in the EU. EFSA Journal, 16(4), e05259. https://doi.org/10.2903/j.efsa.2018.5259

Mozley-Standridge, S. E., Letcher, P. M., Longcore, J. E., Porter, D., \& Simmons, D. R. (2009). Cladochytriales-A new order in Chytridiomycota. Mycological Research, 113(Pt 4), 498-507. https://doi.org/10.1016/j.mycres.2008.12.004

Naville, M., Henriet, S., Warren, I., Sumic, S., Reeve, M., Volff, J.-N., \& Chourrout, D. (2019). Massive Changes of Genome Size Driven by Expansions of Non-autonomous Transposable Elements. Current Biology, 29(7), 1161-1168.e6. https://doi.org/10.1016/j.cub.2019.01.080 
1046 Nguyen, L.-T., Schmidt, H. A., von Haeseler, A., \& Minh, B. Q. (2015). IQ-TREE: A Fast

1047 and Effective Stochastic Algorithm for Estimating Maximum-Likelihood

1048 Phylogenies. Molecular Biology and Evolution, 32(1), 268-274.

1049 https://doi.org/10.1093/molbev/msu300

1050 Oggenfuss, U., Badet, T., Wicker, T., Hartmann, F. E., Singh, N. K., Abraham, L. N.,

1051 Karisto, P., Vonlanthen, T., Mundt, C. C., McDonald, B. A., \& Croll, D. (2021). A

1052 population-level invasion by transposable elements triggers genome expansion in a

1053 fungal pathogen. BioRxiv. https://doi.org/10.1101/2020.02.11.944652

1054 O’Hanlon, S. J., Rieux, A., Farrer, R. A., Rosa, G. M., Waldman, B., Bataille, A., Kosch, T. global amphibian declines. Science (New York, N.Y.), 360(6389), 621-627.

Papkou, A., Guzella, T., Yang, W., Koepper, S., Pees, B., Schalkowski, R., Barg, M.-C., Rosenstiel, P. C., Teotónio, H., \& Schulenburg, H. (2019). The genomic basis of Red Queen dynamics during rapid reciprocal host-pathogen coevolution. Proceedings of the National Academy of Sciences, 116(3), 923-928. https://doi.org/10.1073/pnas.1810402116 genes in eukaryotic genomes. Bioinformatics, 23(9), 1061-1067. https://doi.org/10.1093/bioinformatics/btm071 
1071

1072

1073

1074

1075

1076

Ectomycorrhizal ecology is imprinted in the genome of the dominant symbiotic fungus Cenococcum geophilum. Nature Communications, 7(1), 12662. https://doi.org/10.1038/ncomms 12662

Petersen, T. N., Brunak, S., von Heijne, G., \& Nielsen, H. (2011). SignalP 4.0: Discriminating signal peptides from transmembrane regions. Nature Methods, $8(10)$, 785-786. https://doi.org/10.1038/nmeth.1701

Pietzenuk, B., Markus, C., Gaubert, H., Bagwan, N., Merotto, A., Bucher, E., \& Pecinka, A. (2016). Recurrent evolution of heat-responsiveness in Brassicaceae COPIA elements. Genome Biology, 17(1), 209. https://doi.org/10.1186/s13059-016-1072-3

Plissonneau, C., Stürchler, A., \& Croll, D. (2016). The Evolution of Orphan Regions in Genomes of a Fungal Pathogen of Wheat. MBio, 7(5), e01231-16, /mbio/7/5/e0123116.atom. https://doi.org/10.1128/mBio.01231-16

Pm, L., Cg, V., Me, B., Mj, P., Pf, C., \& Ws, W. (2008). Ultrastructural and molecular analyses of Rhizophydiales (Chytridiomycota) isolates from North America and Argentina. Mycological Research, 112(Pt 7), 759-782. https://doi.org/10.1016/j.mycres.2008.01.025

Powell, M. J., Letcher, P. M., Longcore, J. E., \& Blackwell, W. H. (2018). Zopfochytrium is a new genus in the Chytridiales with distinct zoospore ultrastructure. Fungal Biology, 122(11), 1041-1049. https://doi.org/10.1016/j.funbio.2018.08.005

Price, A. L., Jones, N. C., \& Pevzner, P. A. (2005). De novo identification of repeat families in large genomes. Bioinformatics, 21(SUPPL. 1), 351-358. https://doi.org/10.1093/bioinformatics/bti1018

Raffaele, S., Farrer, R. A., Cano, L. M., Studholme, D. J., MacLean, D., Thines, M., Jiang, R. H. Y., Zody, M. C., Kunjeti, S. G., Donofrio, N. M., Meyers, B. C., Nusbaum, C., \& Kamoun, S. (2010). Genome Evolution Following Host Jumps in the Irish Potato 
1096

1097

1098

1099

1100

1101

1102

1103

1104

1105

1106

1107

1108

1109

1110

1111

1112

1113

1114

1115

1116

1117

1118

1119

1120

Famine Pathogen Lineage. Science, 330(6010), 1540-1543.

https://doi.org/10.1126/science. 1193070

Raffaele, S., \& Kamoun, S. (2012a). Genome evolution in filamentous plant pathogens: Why bigger can be better. Nature Reviews Microbiology, 10(6), 417-430. https://doi.org/10.1038/nrmicro2790

Raffaele, S., \& Kamoun, S. (2012b). Genome evolution in filamentous plant pathogens: Why bigger can be better. Nature Reviews Microbiology, 10(6), 417-430. https://doi.org/10.1038/nrmicro2790

Ramakrishna Rao, K., \& Shanmugasundaram, E. R. B. (1970). Biochemical and genetical studies on host parasite relationship: Role of tyrosinase in pathocenicity and host resistance of two mutants of fusarium vasinfectum Atk. Mycopathologia et Mycologia Applicata, 42(3), 299-304. https://doi.org/10.1007/BF02051959

Robinson, J. T., Thorvaldsdóttir, H., Winckler, W., Guttman, M., Lander, E. S., Getz, G., \& Mesirov, J. P. (2011). Integrative genomics viewer. Nature Biotechnology, 29(1), 24 26. https://doi.org/10.1038/nbt.1754

Rouxel, T., Grandaubert, J., Hane, J. K., Hoede, C., van de Wouw, A. P., Couloux, A., Dominguez, V., Anthouard, V., Bally, P., Bourras, S., Cozijnsen, A. J., Ciuffetti, L. M., Degrave, A., Dilmaghani, A., Duret, L., Fudal, I., Goodwin, S. B., Gout, L., Glaser, N., ... Howlett, B. J. (2011). Effector diversification within compartments of the Leptosphaeria maculans genome affected by Repeat-Induced Point mutations. Nature Communications, 2(1), 202. https://doi.org/10.1038/ncomms1189

Sánchez-Vallet, A., Fouché, S., Fudal, I., Hartmann, F. E., Soyer, J. L., Tellier, A., \& Croll, D. (2018). The Genome Biology of Effector Gene Evolution in Filamentous Plant Pathogens. Annual Review of Phytopathology, 56(1), 21-40. https://doi.org/10.1146/annurev-phyto-080516-035303 
1121 Schrader, L., \& Schmitz, J. (2019). The impact of transposable elements in adaptive

1122 evolution. Molecular Ecology, 28(6), 1537-1549. https://doi.org/10.1111/mec.14794

1123 Schwessinger, B. (2019). High quality DNA from Fungi for long read sequencing e.g.

1124 PacBio. Protocols.Io. https://doi.org/dx.doi.org/10.17504/protocols.io.2yfgftn

1125 Schwessinger, B., \& Rathjen, J. P. (2017). Extraction of High Molecular Weight DNA from

1126 Fungal Rust Spores for Long Read Sequencing. In S. Periyannan (Ed.), Wheat Rust

1127 Diseases. Methods in Molecular Biology (vol 1659, pp. 49-57). Humana Press.

1128 Seppey, M., Manni, M., \& Zdobnov, E. M. (2019). BUSCO: Assessing Genome Assembly

1129 and Annotation Completeness. In M. Kollmar (Ed.), Gene Prediction: Methods and

1130 Protocols (Vol. 1962, pp. 227-245). Springer Science+Business Media.

1131 Shende, R., Wong, S. S. W., Rapole, S., Beau, R., Ibrahim-Granet, O., Monod, M., Gührs,

1132 K.-H., Pal, J. K., Latgé, J.-P., Madan, T., Aimanianda, V., \& Sahu, A. (2018).

1133 Aspergillus fumigatus conidial metalloprotease Mep1p cleaves host complement

$1134 \quad$ proteins. Journal of Biological Chemistry, 293(40), 15538-15555.

1135 https://doi.org/10.1074/jbc.RA117.001476

1136 Smit, A., Hubley, R., \& Green, P. (2015). RepeatMasker Open-4.0.

1137 Spanu, P. D., Abbott, J. C., Amselem, J., Burgis, T. A., Soanes, D. M., Stüber, K., Loren van

1138 Themaat, E. V., Brown, J. K. M., Butcher, S. A., Gurr, S. J., Lebrun, M.-H., Ridout,

1139 C. J., Schulze-Lefert, P., Talbot, N. J., Ahmadinejad, N., Ametz, C., Barton, G. R.,

1140 Benjdia, M., Bidzinski, P., ... Panstruga, R. (2010). Genome Expansion and Gene

1141 Loss in Powdery Mildew Fungi Reveal Tradeoffs in Extreme Parasitism. Science,

$1142330(6010), 1543-1546$. https://doi.org/10.1126/science.1194573

1143 Stamatakis, A. (2006). RAxML-VI-HPC: Maximum likelihood-based phylogenetic analyses

1144 with thousands of taxa and mixed models. Bioinformatics, 22(21), 2688-2690.

1145 https://doi.org/10.1093/bioinformatics/bt1446 
1146 Stanke, M., Diekhans, M., Baertsch, R., \& Haussler, D. (2008). Using native and syntenically

1147 mapped cDNA alignments to improve de novo gene finding. Bioinformatics, 24(5),

1148 637-644. https://doi.org/10.1093/bioinformatics/btn013

1149 Tellier, A., Moreno-Gamez, S., \& Stephan, W. (2014). SPEED OF ADAPTATION AND GENOMIC FOOTPRINTS OF HOST-PARASITE COEVOLUTION UNDER ARMS RACE AND TRENCH WARFARE DYNAMICS. 68, 2211-2224.

1152 Torres, D. E., Oggenfuss, U., Croll, D., \& Seidl, M. F. (2020). Genome evolution in fungal 1153 plant pathogens: Looking beyond the two-speed genome model. Fungal Biology 1154 Reviews, 34(3), 136-143. https://doi.org/10.1016/j.fbr.2020.07.001

1155 Tyler, B. M., Tripathy, S., Zhang, X., Dehal, P., Jiang, R. H. Y., Aerts, A., Arredondo, F. D., 1156 Baxter, L., Bensasson, D., Beynon, J. L., Chapman, J., Damasceno, C. M. B., 1157 Dorrance, A. E., Dou, D., Dickerman, A. W., Dubchak, I. L., Garbelotto, M., Gijzen, 1158 M., Gordon, S. G., ... Boore, J. L. (2006). Phytophthora genome sequences uncover 1159 evolutionary origins and mechanisms of pathogenesis. Science (New York, N.Y.), 1160 313(5791), 1261-1266. https://doi.org/10.1126/science.1128796

1161 van de Vossenberg, B. T. L. H., Warris, S., Nguyen, H. D. T., van Gent-Pelzer, M. P. E., 1162 Joly, D. L., van de Geest, H. C., Bonants, P. J. M., Smith, D. S., Lévesque, C. A., \& 1163 van der Lee, T. A. J. (2019). Comparative genomics of chytrid fungi reveal insights 1164 into the obligate biotrophic and pathogenic lifestyle of Synchytrium endobioticum.

1165 Scientific Reports, 9(1), 8672. https://doi.org/10.1038/s41598-019-45128-9

1166 Van Valen, L. (1973). A NEW EVOLUTIONARY LAW. 1, 1-30.

1167 Vaser, R., \& Sikic, M. (2019). Yet another de novo genome assembler. International 1168 Symposium on Image and Signal Processing and Analysis, ISPA, 2019-Septe, 1471169 151. https://doi.org/10.1109/ISPA.2019.8868909 
1170 Voss, K., Auwera, G. V. der, \& Gentry, J. (2017). Full-stack genomics pipelining with GATK4 + WDL + Cromwell. 18th Annual Bioinformatics Open Source Conference (BOSC 2017), 6. https://doi.org/10.7490/f1000research.1114634.1

1173 Walker, B. J., Abeel, T., Shea, T., Priest, M., Abouelliel, A., Sakthikumar, S., Cuomo, C. A.,

Wang, Q., Jiang, C., Wang, C., Chen, C., Xu, J.-R., \& Liu, H. (2017). Characterization of the Two-Speed Subgenomes of Fusarium graminearum Reveals the Fast-Speed Subgenome Specialized for Adaption and Infection. Frontiers in Plant Science, 8. https://doi.org/10.3389/fpls.2017.00140

Wang, Y., Liang, W., \& Tang, T. (2018). Constant conflict between Gypsy LTR

Wang, Y., Verbrugghe, E., Meuris, L., Chiers, K., Kelly, M., Strubbe, D., Callewaert, N., Pasmans, F., \& Martel, A. (2021). Epidermal galactose spurs chytrid virulence and predicts amphibian colonization. Nature Communications, 12(1), 5788.

1188 Wick, R. R., Judd, L. M., Gorrie, C. L., \& Holt, K. E. (2017). Completing bacterial genome assemblies with multiplex MinION sequencing. Microbial Genomics, 3(10), 1-7. https://doi.org/10.1099/mgen.0.000132 
1195 Wilkinson, G. N., \& Rogers, C. E. (1973). Symbolic Description of Factorial Models for

1196 Analysis of Variance. Journal of the Royal Statistical Society. Series C (Applied

1197 Statistics), 22(3), 392-399. https://doi.org/10.2307/2346786

1198 Winter, D. J., Ganley, A. R. D., Young, C. A., Liachko, I., Schardl, C. L., Dupont, P.-Y.,

1199 Berry, D., Ram, A., Scott, B., \& Cox, M. P. (2018). Repeat elements organise 3D

1200 genome structure and mediate transcription in the filamentous fungus Epichlö

$1201 \quad$ festucae. PLOS Genetics, 14(10), e1007467.

1202 https://doi.org/10.1371/journal.pgen.1007467

1203 Wos, G., Choudhury, R. R., Kolář, F., \& Parisod, C. (2021). Transcriptional activity of

1204 transposable elements along an elevational gradient in Arabidopsis arenosa. Mobile

$1205 \quad$ DNA, 12(1), 7.

1206 Wöstemeyer, J., \& Kreibich, A. (2002). Repetitive DNA elements in fungi (Mycota): Impact

1207 on genomic architecture and evolution. Current Genetics, 41(4), 189-198.

1208 https://doi.org/10.1007/s00294-002-0306-y

1209 Xu, Q., Wang, J., Zhao, J., Xu, J., Sun, S., Zhang, H., Wu, J., Tang, C., Kang, Z., \& Wang,

1210 X. (2020). A polysaccharide deacetylase from Puccinia striiformis f. Sp. Tritici is an

1211 important pathogenicity gene that suppresses plant immunity. Plant Biotechnology

1212 Journal, 18(8), 1830-1842. https://doi.org/10.1111/pbi.13345

1213 Yang, Z. (2007). PAML 4: Phylogenetic analysis by maximum likelihood. Molecular Biology

1214 and Evolution, 24(8), 1586-1591. https://doi.org/10.1093/molbev/msm088

1215 Yang, Z., \& Nielsen, R. (2000). Estimating synonymous and nonsynonymous substitution

1216 rates under realistic evolutionary models. Molecular Biology and Evolution, 17(1),

$1217 \quad 32-43$. 
bioRxiv preprint doi: https://doi.org/10.1101/2021.11.03.467166; this version posted November 4, 2021. The copyright holder for this preprint

(which was not certified by peer review) is the author/funder, who has granted bioRxiv a license to display the preprint in perpetuity. It is made available under aCC-BY 4.0 International license.

1218 Zhang, S.-J., Liu, L., Yang, R., \& Wang, X. (2020). Genome Size Evolution Mediated by

1219 Gypsy Retrotransposons in Brassicaceae. Genomics, Proteomics \& Bioinformatics,

18(3), 321-332. https://doi.org/10.1016/j.gpb.2018.07.009 
bioRxiv preprint doi: https://doi.org/10.1101/2021.11.03.467166; this version posted November 4, 2021. The copyright holder for this preprint (which was not certified by peer review) is the author/funder, who has granted bioRxiv a license to display the preprint in perpetuity. It is made available under aCC-BY 4.0 International license. 
Rhizophydiales
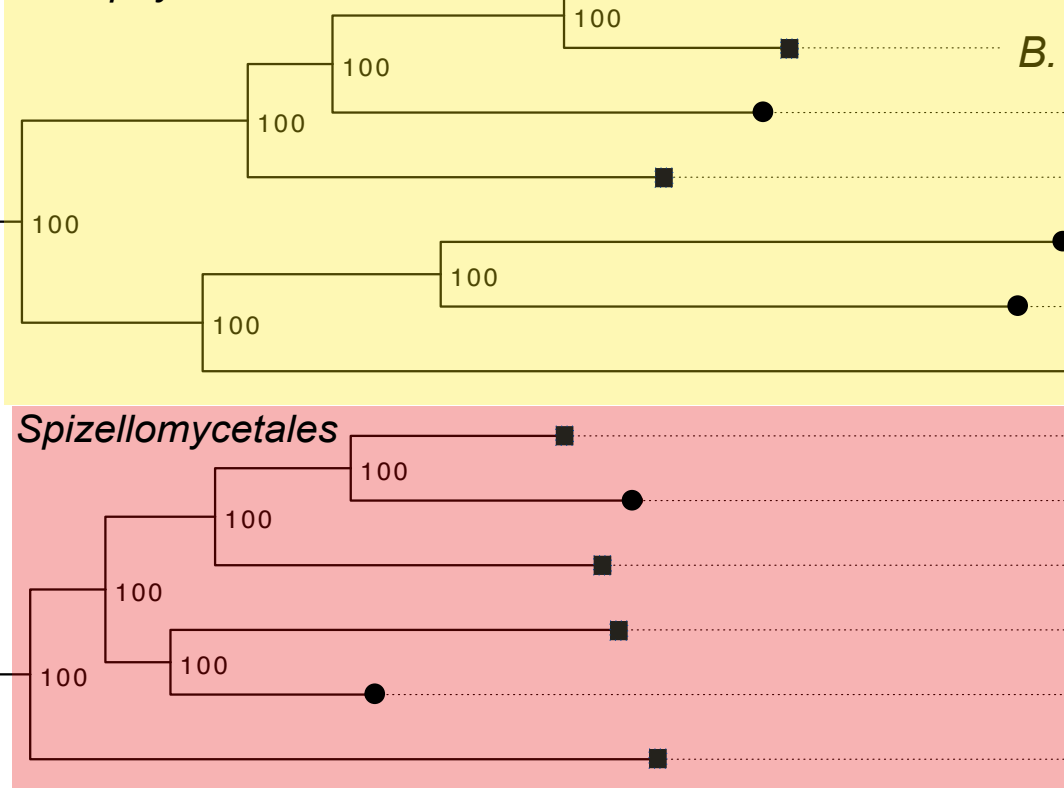

100

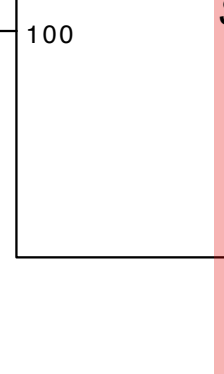

Chytridiales

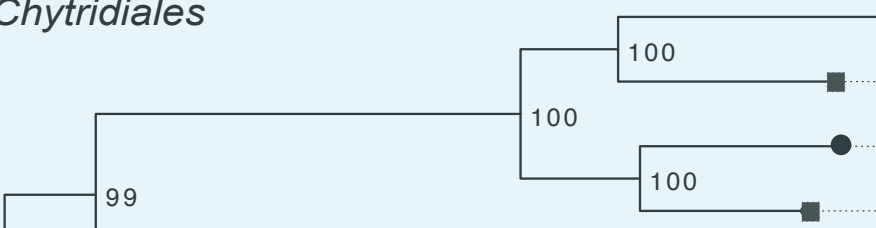

100

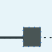

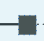

Monoblepharidomycetes

100

100
B. dendrobatidis

B. salamandrivorans

H. polyrhiza

E. helioformis -

- BDMADA_210 -

G. pollinis-pini

- G. haynaldii P. hirtus

G. variabilis F. jonesii

T. arcticum

S. punctuatus

G. semiglobifer

R. globosum

O. mucronatum

Chytriomyces sp.

C. hyalinus

C. polystomum

C. lagenaria

-... G. prolifera

H. curvatum

C. replicatum
Non-repeat intergenic (Mb) Repeats (Mb) Introns (Mb) Coding (Mb)

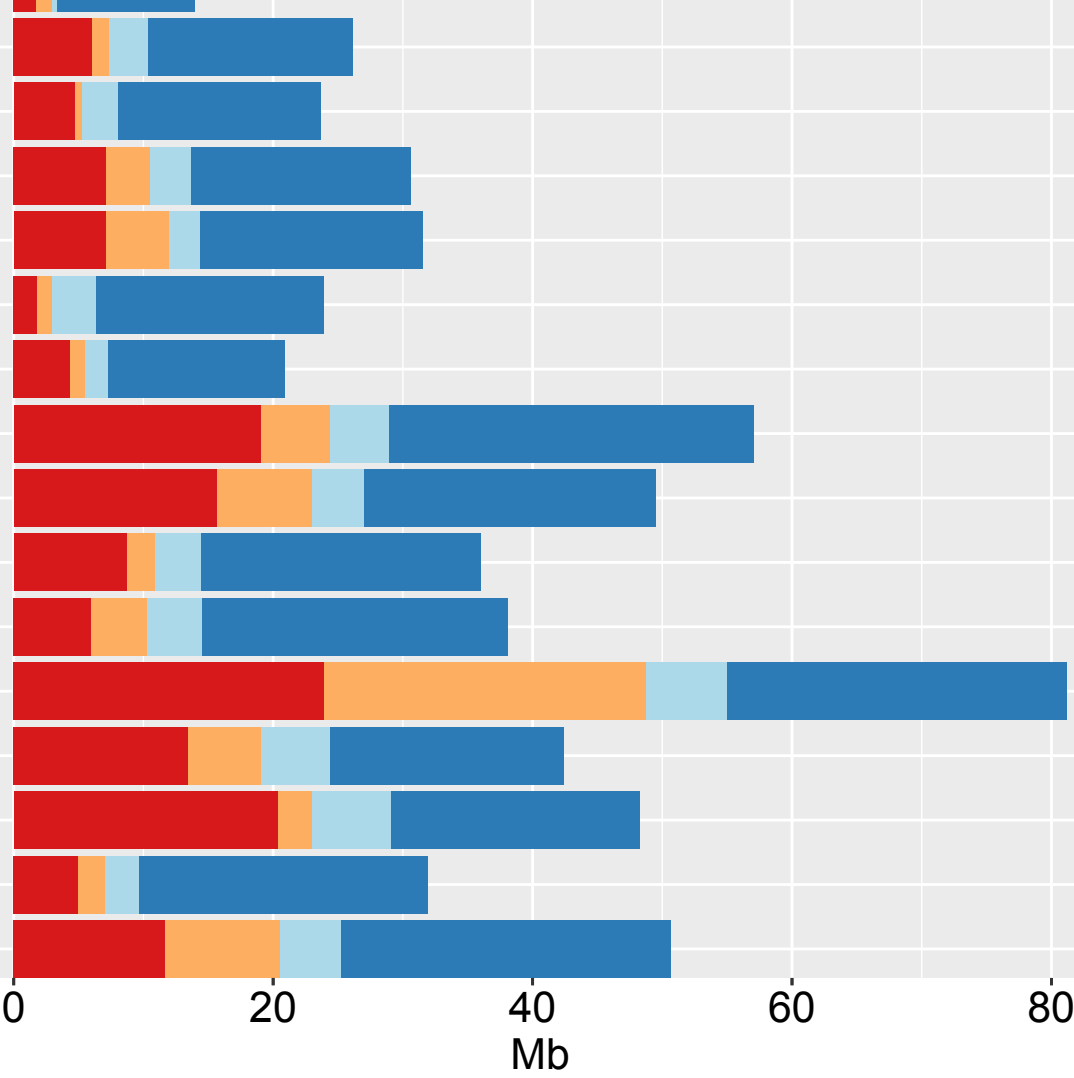




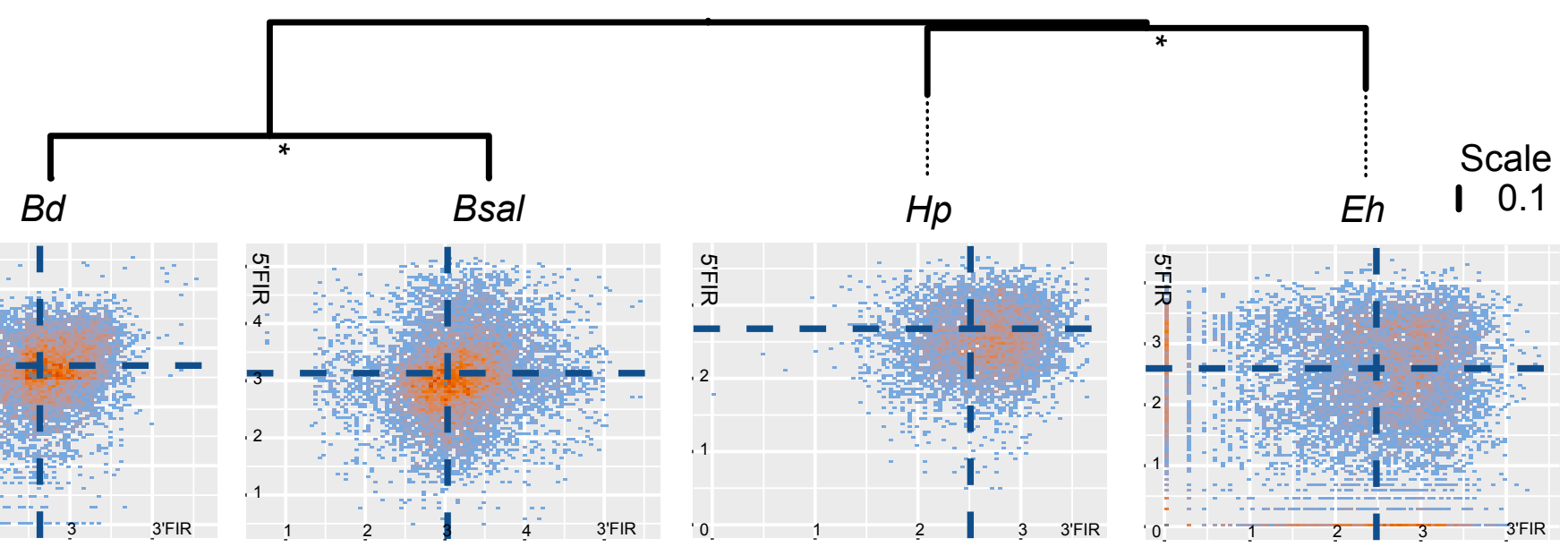

B)

Bsal core conserved genes

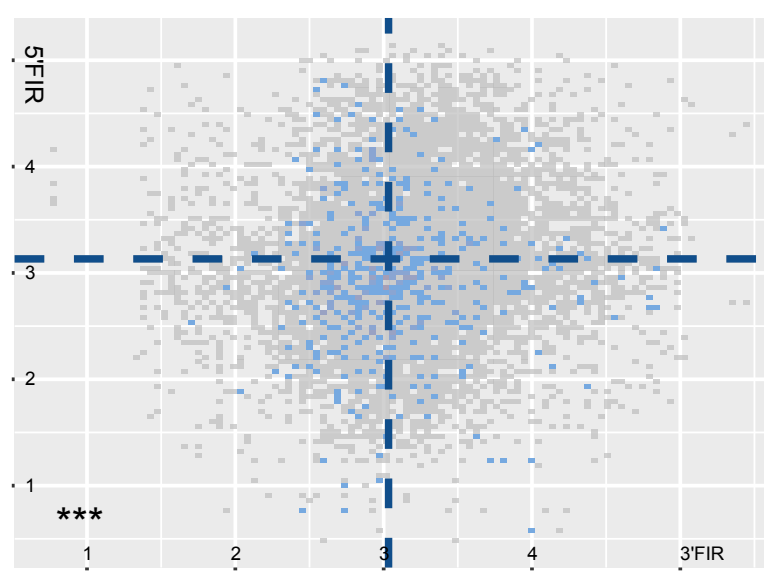

D)

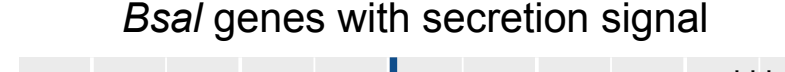

F)

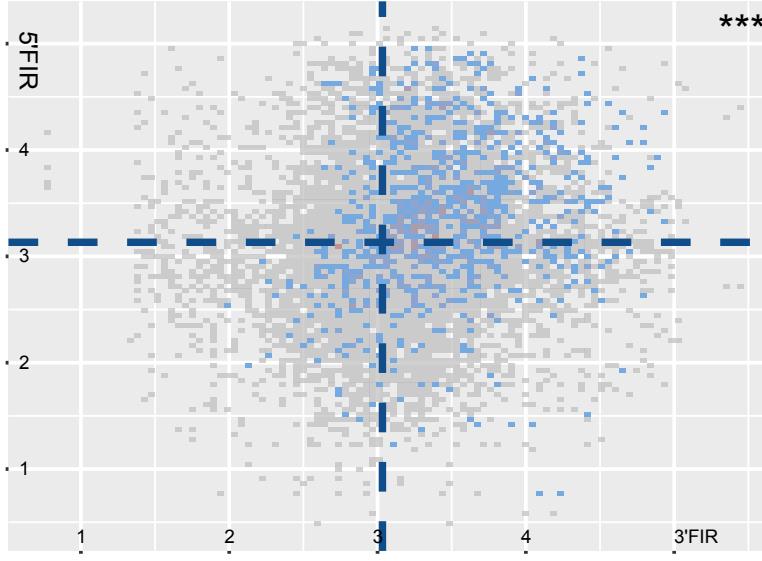

C)

\section{Bsal M36 genes}

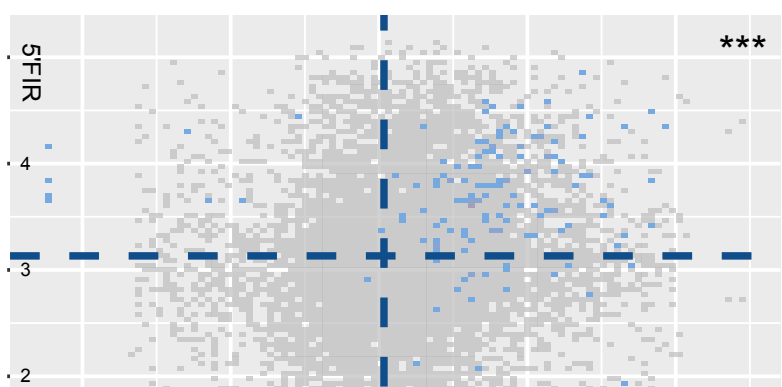

E)

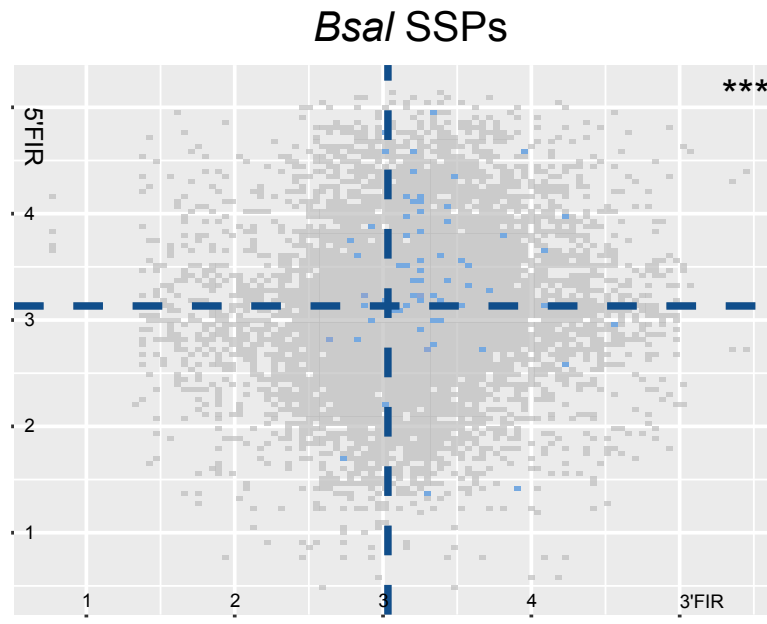

Genes (n)

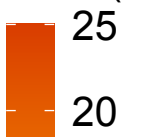

10

Position in genome (Mb)

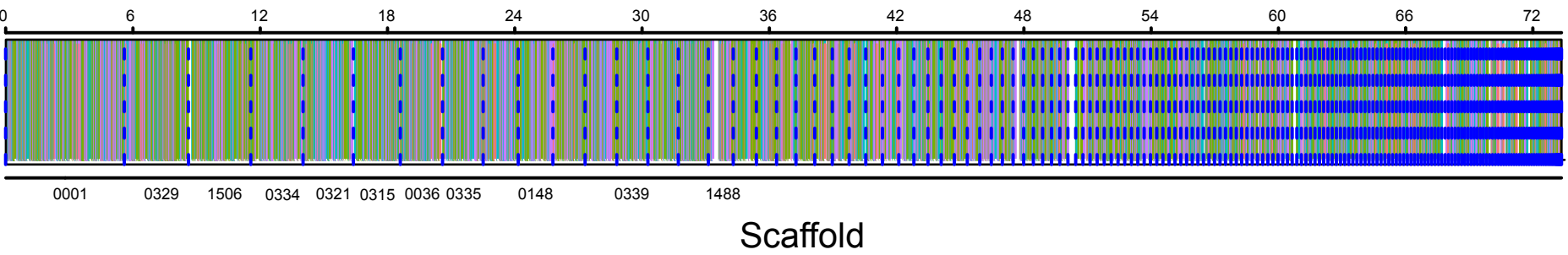




\section{B. salamandrivorans}
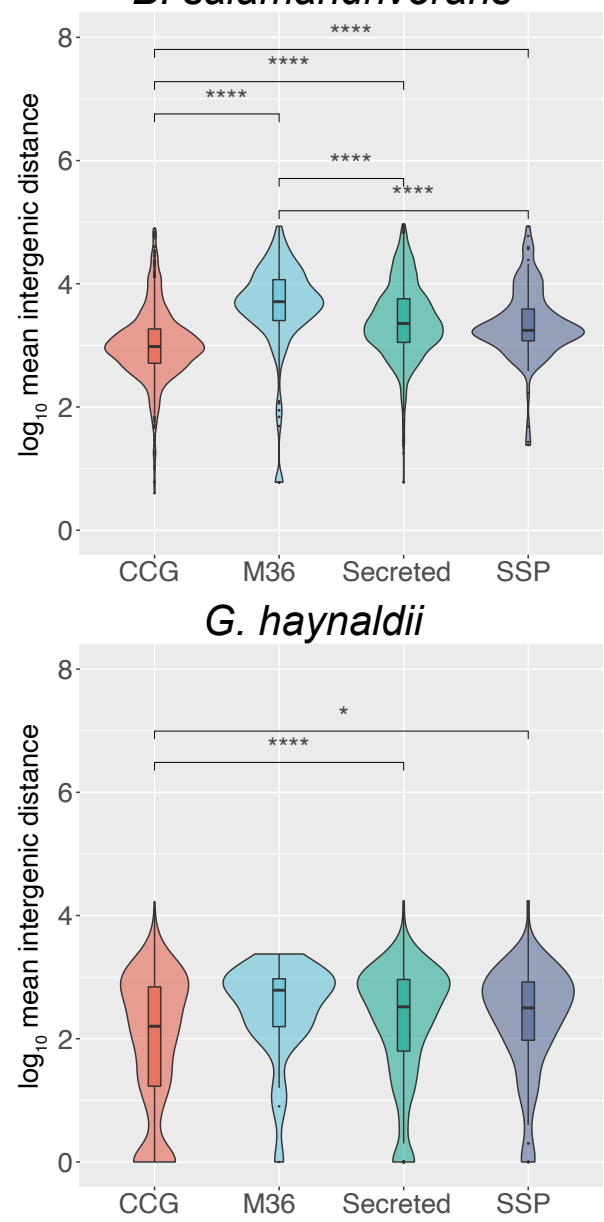

E. helioformis

H. polyrhiza

6.

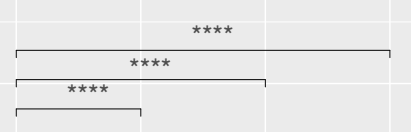

4

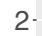

$$
\text { BDMADA_210 }
$$

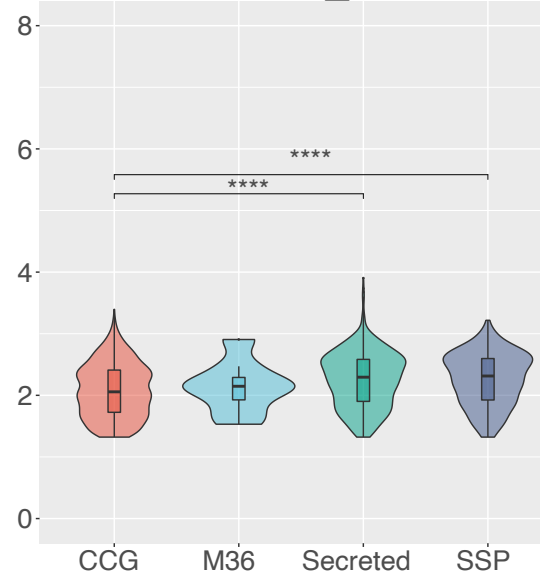

8

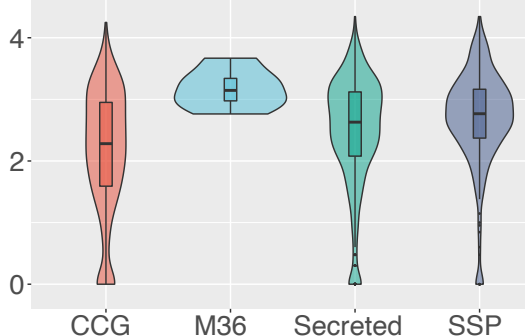

G. pollinis-pini
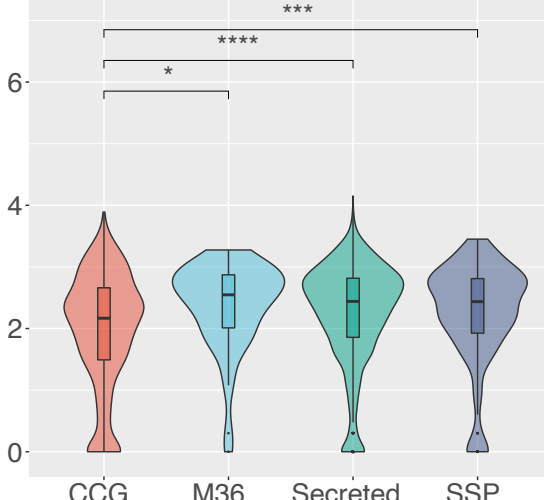
H. polyrhiza

E. helioformis -

B. salamandrivorans-

B. dendrobatidis-
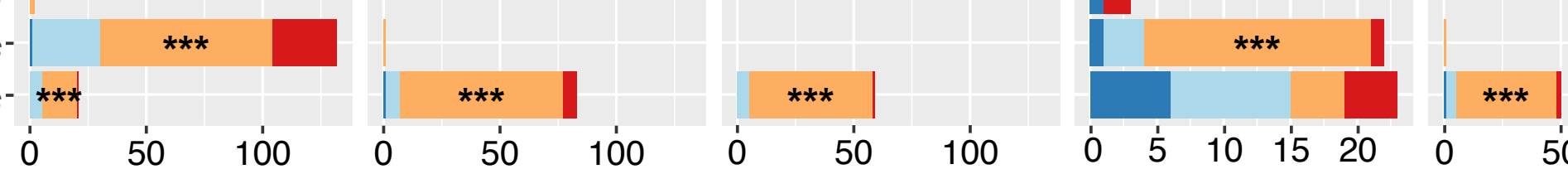

50100

H. polyrhiz

E. helioformis

B. salamandrivorans-

B. dendrobatidis
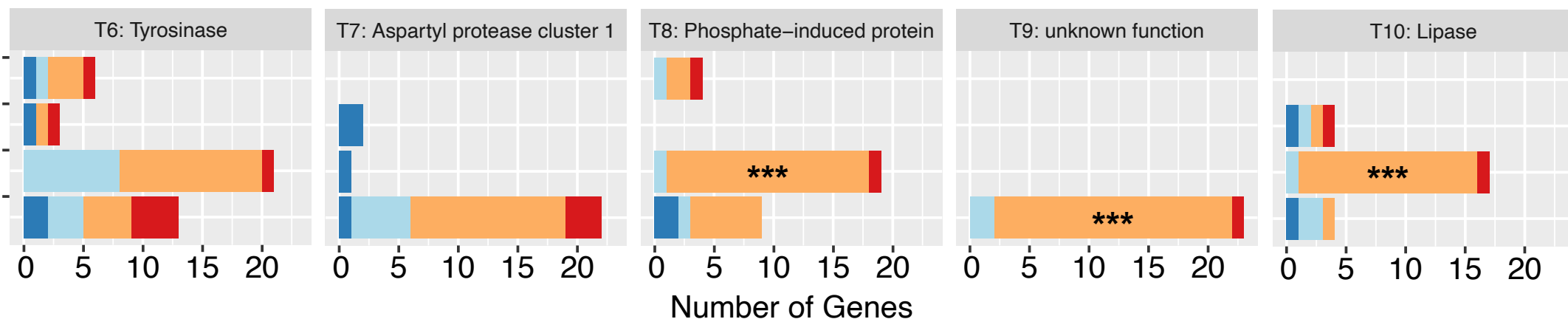

Number of Genes 
